\title{
PASADO, PRESENTE Y FUTURO DE LOS OBJETIVOS DEL DESARROLLO SOSTENIBLE (ODS). LA TECNOLOGÍA COMO CATALIZADOR (O INHIBIDOR) DE LA AGENDA 2030
}

\author{
Autores: Alberto Andreu Pinillos \\ albertoandreu@unav.es \\ Profesor asociado y Director Ejecutivo del Máster de Dirección de Personas \\ de la Universidad de Navarra \\ ORCID: https://orcid.org/0000-0003-1312-0899 \\ José-Luis Fernández-Fernández \\ jlfernandez@icade.comillas.edu \\ Director de la Cátedra Iberdrola de Ética Económica y Empresarial \\ de la Universidad Pontificia Comillas \\ ORCID: http://orcid.org/0000-0002-2344-7169 \\ Joaquín Fernández Mateo \\ joaquin.fernandez@urjc.es \\ Universidad Rey Juan Carlos \\ ORCID: https://orcid.org/0000-0002-9560-5197
}




\section{Resumen}

Este trabajo tiene como objetivo presentar el origen de los Objetivos de Desarrollo Sostenible, entender su situación actual -especialmente por el impacto que podrá tener en ellos la tecnología- y avanzar sus posibles efectos en 2030. Para ello, se estructura en tres partes. En primer lugar, lleva a cabo un repaso histórico de los instrumentos que han contribuido a generalizar el interés por el discurso sobre un desarrollo económico que no ponga en peligro ni el futuro del planeta ni las necesidades de las generaciones por venir. De la convergencia de dichos instrumentos -y de su concreción en distintas herramientas multilaterales-, se derivan los actuales Objetivos de Desarrollo Sostenible -ODS, en español; SDG, por sus siglas en inglés, Sustainable Development Goals- a los que nos aproximamos con talante inequívocamente favorable, pero de una manera crítica. En segundo lugar, el trabajo llama la atención respecto a cómo la tecnología y la digitalización de la economía y la sociedad -que constituyen rasgos particulares del presente momento histórico-, constituyen y representan el verdadero fermento de casi toda la tarea implícita en la enumeración y despliegue de los diecisiete ODS. Por último, se identifican y señalan algunas de las herramientas tecnológicas más señeras que, a juicio de los coautores de este trabajo, pudieran servir para la consecución de la denominada Agenda 2030. La tecnología, en efecto, puede favorecer la consecución de acuerdos y derechos, en tanto que catalizadora de los ODS. Sin embargo, declaramos también ciertos límites debidos a la complejidad de la propia Agenda 2030. Dicha complejidad reside, sobre todo, en el carácter holístico e interconectado que evidencian los problemas y retos a los que nos enfrentamos.

Palabras clave: Objetivos de Desarrollo Sostenible; sostenibilidad; responsabilidad social; Agenda 2030; transformación digital; tecnología.

\section{Past, Present and Future of the Sustainable Development Goals (SDG). Tecnology as catalyst (or inhibitor) of 2030 Agenda}

\section{Abstract}

This paper aims to present the origin of the Sustainable Development Goals, understand their current situation -especially the impact that technology may have on them-, and advance their possible effects in 2030. So, to do this, it is structured in three parts. On the one hand, it carries out a historical review of the instruments that have contributed to generalise the interest for the discourse on an economic development that does not endanger neither the future of the planet nor the needs of the generations to come. From the convergence of these instruments -and their concretion in different multilateral tools- derive the current Sustainable Development Goals (SDG), to those we approach with an 
unequivocally favorable disposition, but in a critical way. Secondly, the article draws attention to how technology and the digitalisation of the economy and society -which are particular features of the present historical moment- constitute and represent the true ferment of almost the entire task implicit in the enumeration and deployment of the seventeen SDGs. Finally, it identifies and points out some of the most outstanding technological tools that, in the opinion of the co-authors of this work, could be used to achieve the so-called Agenda 2030. Technology, in effect, can favour the achievement of agreements and rights, as a catalyst for SDGs. However, we also declare certain limits due to the complexity of Agenda 2030 itself. This complexity lies, above all, in the holistic and interconnected nature of the problems and challenges we face.

Key words: Sustainable Development Goals; sustainability; social responsibility; 2030 Agenda; digital transformation, technology.

Fecha de recepción: 16/11/2019.

Fecha de aceptación: 10/12/2019.

\section{INTRODUCCIÓN}

La denominada Agenda 2030, en la que se insertan los diecisiete Objetivos de Desarrollo Sostenible -ODS, en español; SDG, por sus siglas en inglés, Sustainable Development Goals - constituye, sin duda, uno de los mayores triunfos del multilateralismo de los últimos tiempos. Su propuesta en el año 2015 representó un signo de unidad entre los Estados miembros de la ONU, comprometidos expresamente a colaborar, entre otras cosas, en la erradicación de la pobreza extrema, en la reducción de la desigualdad entre pueblos y personas, y en mantenerse unidos en esfuerzos conjuntos, cara a la protección del planeta.

Quienes suscribimos como coautores este trabajo asumimos la pertinencia de los ODS y encarecemos la necesidad de empeñarse en conseguirlos de aquí al año 2030. Con todo, consideramos también que el mejor servicio que desde la Academia se puede hacer a la causa es abordar su estudio de forma objetiva y factual. Es decir: analizar a fondo el discurso de los ODS, con vistas a identificar, entre otras cosas, sesgos e inconsistencias teóricas. Y, en su caso, contribuir a depurarlos del barniz ideológico que muchas voces les atribuyen ipor qué precisamente son diecisiete y no catorce o cincuenta y tres?; ¿qué lógica económica está detrás de ellos y qué alternativas se quieren obviar al proponerlos?; ¿están todos los que son y son todos los que están?; ¿no se echan de menos voces alternativas al sistema?; 
¿es razonable pensar que con ellos se vayan a solucionar los verdaderos problemas de la desigualdad, la sostenibilidad de los procesos y el desarrollo de todos los seres humanos? ¿Responden a una determinada ideología?

Por ello -insistimos-, al margen de que, en el aspecto práctico, apostemos por la colaboración franca de todos los concernidos -gobiernos y administraciones, sociedad civil, organismos multilaterales y empresas-, con vistas a la consecución de los citados Objetivos, las cuestiones y los interrogantes que acabamos de formular tienen suficiente calado como para prestarles atención; o cuando menos, para dejar constancia de evidentes lagunas e insuficiencias teóricas; de desatención a otras voces alternativas, poco tenidas en cuenta a la hora de instrumentar la narrativa de los ODS. Esta circunstancia, por lo demás, quizás pueda tener incidencia a la hora de obtener resultados y de evaluar las concreciones prácticas como más o menos exitosas. Pues, más allá de la suerte de retórica persuasiva que el relato de los ODS representa, caben, entre otras cosas, prácticas gubernamentales ineficientes, por ejemplo, a la hora de aplicar recursos; o sobreactuaciones por parte de empresas y otros agentes económicos que acaben secuestrando el discurso y convirtiéndolo en puro maquillaje, en una versión más del efecto escaparate, sin acabar de llegar al fondo de las cuestiones.

Por ello, no estaría de más llevar a cabo un análisis crítico del discurso de los ODS, al modo como Jane Briant Carant hace en un incisivo trabajo de hace un par de años (Briant, 2017), comparándolos con sus inmediatos precedentes, esto es, con los denominados Objetivos del Milenio, en vigor desde el año 2000 al 2015. Con todo, no es nuestro objetivo en este momento desarrollar por menudo la crítica del discurso de los ODS. Bástenos con dejar constancia de que, en efecto, el relato ofrece flancos desguarnecidos e insuficiencias palmarias. Por ejemplo, se afirma que la formulación de 17 Objetivos y 169 metas resulta excesivamente expansiva y que dificulta que los gobiernos puedan acopiar y aplicar recursos suficientes. Ello, de paso, les permitirá afirmar la consecución de logros parciales, sin tener que empeñarse a fondo en la solución de retos clave.

Otro aspecto que añadir en el Debe de los ODS es el hecho de que no todos los Objetivos son igualmente prioritarios, siendo así que, por ejemplo, el de la educación es condición de posibilidad de la consecución de otros varios; y que, en consecuencia, no procede situarlos todos en el mismo nivel. Por lo demás, hay quien llega incluso a ver contradicciones entre Objetivos y metas. Por ejemplo, la meta 1 del Objetivo 4, sería incompatible con la meta 6 del Objetivo 8. En definitiva, "such contradictions make it difficult to determine how the UN perceives these goals working together and how they can be simultaneously achieved" (Briant, 2017, p. 33).

Pese a la mejor de las voluntades que quepa suponer a quienes desde la ONU impulsaron tanto los Objetivos del Milenio, cuanto los actuales, sus herederos, Objetivos de Desarrollo Sostenible, no cabe duda de que, por ir a uno de los puntos 
cruciales, el enfoque con que se aproximan a la erradicación de la pobreza extrema, constituye un programa -en el marco del paradigma keynesiano, el feminismo liberal y el neoliberalismo-, entre otros varios programas posibles que, sin embargo, no han sido tenidos en consideración.

La carga ideológica implícita en las propuestas económicas y estratégicas de los ODS resulta evidente; y, en consecuencia, la crítica de la misma deviene necesaria, si de veras se busca avanzar en la solución de aquellos problemas identificados. En este sentido, cabe insistir en el hecho de que también la ciencia es un constructo social -y las Ciencias Humanas, las Ciencias Sociales y las Económicas, aún en mayor medida-; y que, como la neutralidad y la asepsia resultan empeños imposibles, la honradez intelectual pediría reconocer el hecho, suspender un tanto el juicio, poner sordina a la pretensión de agotar las providencias desde la propuesta de los ODS, por bien intencionada que se la quiera suponer. Hay, ciertamente, formulaciones distintas de lo que se haya de entender, por ejemplo, bajo el concepto-constructo de pobreza y su deseable erradicación. En consecuencia, no cabe sino suscribir la tesis de Briant Carant, cuando afirma: "Critical discourse analysis uncovers how dominant social discourses delineate social phenomena, such as poverty, while articulating preferred solution frames that tend to reinforce existing institutional relationships" (Briant, 2017, p. 17).

En estos cuatro años que ya van transcurridos desde que se formularan los ODS, los informes nos hablan de cómo se pueden identificar ya ciertos avances e indiscutibles pasos adelante en la consecución de los Objetivos (Naciones Unidas, 2019). Con todo, aún queda un largo camino por recorrer y urge concitar la voluntad política y elaborar proyectos bien concretos y realistas que se sustancien en la puesta en marcha de acciones que contribuyan a acelerar el proceso (Gorrochategui, Martins de Oliveira, Hernández \& Moreno, 2016).

La lista de tareas pendientes de acometer en los próximos, digamos, treinta años -es decir, ampliando el alcance temporal más allá del que contemplan los ODS y fijando la mirada en torno al año 2050 - resulta fácil de enumerar: habría que eliminar gradualmente el uso del carbón y del gas natural; aumentar la utilización de las energías renovables; trazar un camino para que la energía nuclear, de aquí a entonces, pueda suministrar entre un $1 \%$ y un $28 \%$ de la electricidad necesaria; eliminar el carbono de la atmósfera; modificar hábitos alimenticios que transformen los modelos de cultivo agrícola y favorezcan la presencia de masa forestal; hacer un uso más eficiente de la energía. Y, por encima de todo, investigar, innovar, aprovechar las posibilidades que el desarrollo tecnológico-digital nos ofrece ya, a través de la conectividad, las plataforma, la inteligencia artificial, el blockchain, los algoritmos, la gestión eficiente y ética de los macro-datos y su análisis... para poner en el centro a las personas, no dejar a nadie atrás; y curar un planeta herido que constituye la condición de posibilidad de la vida y el desarrollo -que, tal vez, no crecimiento- sostenible. 
Resulta obvio, como apuntábamos más arriba, que conseguir las 169 metas que emanan de los objetivos propuestos va a resultar extremadamente difícil desde un punto de vista técnico. Pero resultará imposible sin la opción moral de empeñarse por ello. Y, sobre todo, sin la voluntad firme y perseverante de implicarse y colaborar entre todos. Pues se trata de una tarea global: requiere el concurso de los Organismos Multilaterales, así como de los Estados y de las Administraciones Públicas. También precisa de la implicación de la Sociedad Civil -ONG, Universidades, Iglesias...-; y de los ciudadanos particulares. Y, por supuesto, todo ello tiene que estar en la estrategia de las empresas y en la agenda de todas las organizaciones económicas.

Tras este apartado inicial de enmarque, en lo que sigue, ofreceremos un recorrido histórico por los hitos más significados del discurso de la sostenibilidad, conectándolo con el fenómeno de la Responsabilidad Social de la Empresa, tanto en su vertiente teórica, cuanto en las aplicaciones y providencias prácticas en que ha venido cristalizando en las últimas décadas.

Tras ello, en los dos siguientes apartados pondremos el foco en la tecnología como condición de posibilidad y acelerador en la dinámica de la consecución de cada uno de los diecisiete Objetivos de Desarrollo Sostenible. Nos detendremos en cada uno de ellos al respecto. Cerramos el trabajo con unas conclusiones de claro sesgo ético, a partir de las cuales quepa avanzar, tanto en el plano teórico, cuanto en el práctico, en el camino hacia una empresa responsable, una economía sostenible y, en definitiva, un mundo más humano.

\section{UNA MIRADA HISTÓRICA A LA RESPONSABILIDAD Y LA SOSTENIBILIDAD}

El movimiento de la Responsabilidad Social Corporativa o Responsabilidad Social de la Empresa (en adelante RSC) tiene precedentes desde, cuando menos, los años cincuenta del pasado siglo XX (Bazán, Morena \& Cortés, 2016; Gosch \& Duque, 2016). Un hito significativo, por lo demás, lo representaron los trabajos de Milton Friedman (Friedman, 1966; Friedman \& Friedman,1990). Este economista contribuyó a que la narrativa de la RSC se afinara y pudiera llegar a convertirse en la Teoría de Empresa y en el modelo de gestión que hoy representa (Gjerdrum, 2015). Precisamente debido a la contundencia con que se oponía a la pretensión teórico-práctica de que las empresas hubieran de tener alguna responsabilidad social, más allá del estricto cumplimiento de la legalidad vigente y del respeto a las buenas costumbres mercantiles.

Con todo, a los efectos que nos ocuparán en este trabajo, tomaremos el Pacto Mundial o Global Compact del 31 de enero de 1999, como el punto de origen en el que cristalizan en la práctica múltiples intuiciones y providencias que habían 
venido jalonando el camino de lo que representa esta filosofía de empresa desde las décadas anteriores. De hecho, el Pacto Mundial, emanado desde la Organización de las Naciones Unidas (ONU), constituyó en su momento la mayor iniciativa voluntaria de Responsabilidad Social Empresarial que había tenido lugar hasta entonces en el mundo. Por lo demás, hay que recordar que el Pacto Mundial no nació ni como un instrumento de regulación, ni a la manera de un código de conducta internacional con fuerza jurídica obligatoria, ni tampoco como un organismo para formular normativas internacionales. Se creó como una iniciativa de carácter voluntario para fomentar entre las empresas un liderazgo comprometido para ayudar a afrontar una globalización ordenada. Y es que, por lo demás, el proceso de globalización se sitúa en el origen de la Responsabilidad Social Corporativa con un importante impacto sobre empresas multinacionales y la sociedad civil. La finalidad declarada del Pacto Mundial fue la de incorporar los siguientes diez Principios en las actividades empresariales de todo el mundo:

\section{Derechos Humanos}

- Principio N. 1. Apoyar y respetar la protección de los derechos humanos.

- Principio N. 2. No ser cómplice de abusos de los derechos.

\section{Ámbito Laboral}

- Principio N. ${ }^{\circ}$ 3. Apoyar los principios de la libertad de asociación y sindical y el derecho a la negociación colectiva.

- Principio N. 4 . Eliminar el trabajo forzoso y obligatorio.

- Principio N. 5. Abolir cualquier forma de trabajo infantil.

- Principio N. 6. Eliminar la discriminación en materia de empleo y ocupación.

\section{Medio Ambiente}

- Principio N. 7. Las empresas deberán mantener un enfoque preventivo que favorezca el medio ambiente.

- Principio N.o 8. Las empresas deben fomentar las iniciativas que promuevan una mayor responsabilidad ambiental.

- Principio N.o 9. Las empresas deben favorecer el desarrollo y la difusión de las tecnologías respetuosas con el medio ambiente.

\section{Anti - Corrupción}

- Principio N.ำ 10. Las empresas e instituciones deberán trabajar contra la corrupción en todas sus formas, incluidos extorsión y soborno.

(Pacto Mundial) 
Además, el Pacto Mundial desencadenó toda una serie de instrumentos multilaterales e internacionales generando la siguiente construcción institucional:

\begin{tabular}{|c|c|}
\hline Iniciativa y fecha & Concepto \\
\hline $\begin{array}{l}\text { Global Compact } \\
\text { Enero de } 1999\end{array}$ & $\begin{array}{l}\text { Iniciativa voluntaria en la que las empresas } \\
\text { se comprometen a alinear sus estrategias y } \\
\text { operaciones con diez principios universal- } \\
\text { mente aceptados en cuatro grandes áreas: } \\
\text { derechos humanos, estándares laborales, } \\
\text { medio ambiente y anti-corrupción. (supra). }\end{array}$ \\
\hline $\begin{array}{l}\text { Dow Jones Sustainability Index (DJSI) } \\
\text { Septiembre de } 1999 \text {, revisados en } 2010 .\end{array}$ & $\begin{array}{l}\text { El Dow Jones Sustainability Group Index } \\
\text { (DJSGI) es una familia de índices usados para } \\
\text { identificar y seguir el desempeño sostenible } \\
\text { de las compañías. Para poder entrar en él se } \\
\text { deben cumplir unos requisitos establecidos } \\
\text { en base a criterios económicos, ambientales } \\
\text { y sociales a largo plazo. Empresas, ONGs y } \\
\text { agencias gubernamentales hacen referencia } \\
\text { al DJSGI para demostrar la importancia de } \\
\text { integrar economía, medio ambiente y factores } \\
\text { sociales en la gestión de las empresas, y así } \\
\text { incrementar los beneficios de los accionistas } \\
\text { sin perder de vista la trasparencia de la } \\
\text { actividad empresarial. Como resultado, } \\
\text { el DJSGI permite legitimar y liderar los } \\
\text { esfuerzos en mejorar la sostenibilidad de las } \\
\text { compañías globales. El objetivo del índice no } \\
\text { es jerarquizar las empresas por sostenibilidad, } \\
\text { sino compararlas con las empresas de su mismo } \\
\text { sector y tomar el 10\% de las más sostenibles } \\
\text { en cada sector, con el objetivo de lograr el } \\
15 \% \text { de la capitalización en los supersectores } \\
\text { (banca, servicios públicos, tecnología, bienes } \\
\text { de consumo, alimentos y bebidas, etc.). }\end{array}$ \\
\hline $\begin{array}{l}\text { Norma Marco AA1000 } \\
\text { Noviembre de } 1999\end{array}$ & $\begin{array}{l}\text { Norma desarrollada por el Institute of Social } \\
\text { and Ethical Accountability que comprende } \\
\text { un conjunto de requisitos para ayudar a las } \\
\text { empresas a evaluar distintos parámetros de } \\
\text { comportamiento encaminados a medir la } \\
\text { responsabilidad de éstas y cómo se integran } \\
\text { estos principios en su actividad diaria con } \\
\text { todos los stakeholders. }\end{array}$ \\
\hline
\end{tabular}




\begin{tabular}{|c|c|}
\hline Iniciativa y fecha & Concepto \\
\hline $\begin{array}{l}\text { Global Reporting Iniciative (GRI) } \\
\text { 1999, revisión } 2016\end{array}$ & $\begin{array}{l}\text { Institución independiente cuyo principal } \\
\text { objetivo fue armonizar y estandarizar la } \\
\text { elaboración de memorias de sostenibilidad } \\
\text { para aquellas empresas que deseen medir y } \\
\text { reportar su desempeño económico, social y } \\
\text { medioambiental. A finales de } 2016 \text { se pu- } \\
\text { blicaron nuevos estándares que se aplican a } \\
\text { todos los informes desde } 1 \text { de julio de } 2018 \text {. }\end{array}$ \\
\hline $\begin{array}{l}\text { International Standard on Assurance } \\
\text { Engagements (ISAE 3000, previamente } \\
\text { ISAE 100) } \\
\text { Junio de 2000, revisión diciembre } 2013\end{array}$ & $\begin{array}{l}\text { Marco básico para auditorías de gran escala } \\
\text { sobre procesos en materia no financiero-con- } \\
\text { table. Estas auditorías incluyen aspectos } \\
\text { medioambientales y de sostenibilidad, au- } \\
\text { ditando las memorias de sostenibilidad, los } \\
\text { sistemas de información y control y los proce- } \\
\text { sos de gobierno corporativo principalmente. }\end{array}$ \\
\hline $\begin{array}{l}\text { Directrices de la OCDE para empresas } \\
\text { multinacionales } \\
\text { Junio de } 2000 \text {, revisión } 2011\end{array}$ & $\begin{array}{l}\text { Conjunto de recomendaciones formuladas } \\
\text { por los gobiernos a las empresas multina- } \\
\text { cionales que operan en o desde los países } \\
\text { miembros, en materias tales como: empleo, } \\
\text { relaciones industriales, derechos humanos, } \\
\text { medio ambiente, transparencia, anticorrup- } \\
\text { ción, ciencia y tecnología, entre otros, y } \\
\text { que constituyen un marco voluntario de } \\
\text { principios y estándares para la empresa } \\
\text { responsable. Las directrices de la OCDE } \\
\text { para empresas multinacionales no son un } \\
\text { estándar adicional a los ya existentes en } \\
\text { el marco internacional en relación con el } \\
\text { desarrollo sostenible y las empresas, sino que } \\
\text { constituyen una integración coherente de } \\
\text { los instrumentos preexistentes enfocada a su } \\
\text { aplicación práctica por parte de las empresas. }\end{array}$ \\
\hline $\begin{array}{l}\text { Sustainability Accounting Standards } \\
\text { Board (SASB) } \\
\text { Julio de } 2011\end{array}$ & $\begin{array}{l}\text { El Sustainability Accounting Standards Board } \\
\text { (SASB) se fundó en julio de } 2011 \text { para } \\
\text { desarrollar y difundir nuevas normas de } \\
\text { evaluación de la sostenibilidad. SASB es } \\
\text { una organización sin ánimo de lucro que } \\
\text { busca crear estándares de sostenibilidad en } \\
\text { la industria para la divulgación y el reco- } \\
\text { nocimiento de los impactos ambientales, }\end{array}$ \\
\hline
\end{tabular}




\begin{tabular}{|c|c|}
\hline Iniciativa y fecha & Concepto \\
\hline & $\begin{array}{l}\text { sociales y de buen gobierno de las empresas } \\
\text { que cotizan en bolsa en los EEUU. Está } \\
\text { diseñada como guía para la presentación } \\
\text { de información a la Comisión de Valores } \\
\text { y Bolsas en EEUU por las empresas que } \\
\text { transan sus valores en el mercado de ese } \\
\text { país (unas 13.000), dondequiera que estén } \\
\text { domiciliadas. La intención de SASB es } \\
\text { proporcionar a los inversores mayor infor- } \\
\text { mación sobre las acciones en las que ellos } \\
\text { o sus fondos de inversión estaban invirtien- } \\
\text { do, y permitir a los inversores y analistas } \\
\text { financieros comparar el rendimiento en } \\
\text { cuestiones sociales y ambientales críticas } \\
\text { dentro de una industria. }\end{array}$ \\
\hline $\begin{array}{l}\text { Focusing Capital on the Long Term } \\
\text { (FCLT) } \\
2013\end{array}$ & $\begin{array}{l}\text { Focusing Capital on the Long Term (FCLT) } \\
\text { comenzó en } 2013 \text { como una iniciativa de la } \\
\text { Junta de Inversiones del Plan de Pensiones } \\
\text { de Canadá y de McKinsey E Company, cuyos } \\
\text { líderes de la época, Mark Wiseman y Domi- } \\
\text { nic Barton, observaron una presión a corto } \\
\text { plazo sobre los inversores y directores ejecu- } \\
\text { tivos con los que trabajaban. El mensaje de } \\
\text { la iniciativa hizo que el mundo financiero } \\
\text { tomara nota y, sobre todo, marcó la pauta } \\
\text { para que los que participan en los mercados } \\
\text { de capitales puedan corregir sus errores. Con } \\
\text { este espíritu, la Junta de Inversiones del } \\
\text { Plan de Pensiones de Canadá y McKinsey, } \\
\text { junto con BlackRock, The Dow Chemical } \\
\text { Company y Tata Sons, establecieron FCLT- } \\
\text { Global. Como organización independiente } \\
\text { sin fines de lucro, FCLTGlobal trabaja para } \\
\text { fomentar un enfoque a largo plazo en la } \\
\text { toma de decisiones empresariales y de } \\
\text { inversión. }\end{array}$ \\
\hline
\end{tabular}

(Andreu, 2017 y elaboración propia) 
En un artículo publicado en 1970 en el New York Times, Milton Friedman decía que solo "hay una y solo una responsabilidad social del negocio: usar sus recursos y participar en actividades destinadas a aumentar sus beneficios siempre y cuando se mantenga dentro de las reglas del juego, es decir, se involucre en una competencia abierta y libre sin engaños ni fraude" (Friedman, 1970). Esta visión correspondería a enfoques liberales que defenderían la desregulación de los mercados, los procesos de privatización y la reducción de la carga tributaria que conduciría a un debilitamiento del Estado (Friedman, 1966; Hayek, 2009). La economía neoclásica y varias teorías de gestión asumen que el objetivo de la corporación es la maximización de los beneficios. El gobierno, los mercados o el sistema de precios serían el resultado de un mecanismo espontáneo de generación de orden. Sin embargo, esta "entronización" del mercado, como categoría absoluta, obviaría su condición de posibilidad (Fernández-Mateo, 2015). Se trata de la cultura, el contexto que hace posible la interiorización de los valores y la configuración del orden ético, de origen no mercantil. El sustrato cultural haría posible el desarrollo de una sociedad de sujetos éticos, concebidos como polos de autogobierno. Sin embargo, estos elementos culturales habrían quedado obviados por los pensadores liberales, o tratados de forma periférica dado el predominio de la deontología y el cumplimiento de la ley (ya sea justa o injusta).

Frente al enfoque de Friedman, Edward Freeman (1984) entendió que la idea básica de crear valor para los stakeholders es bastante simple. Una organización puede entenderse como un conjunto de relaciones entre grupos que tienen un interés en las actividades que conforman el negocio. Hacer negocios tiene que ver con cómo los clientes, proveedores, empleados, financiadores, las comunidades y los gestores interactúan y crean valor. Entender un negocio es saber cómo funcionan estas relaciones. Y el trabajo del directivo o del empresario es administrar y dar forma a estas relaciones. Esta manera de ver los negocios por parte de Freeman supuso un cambio sustancial respecto a los planteamientos de Friedman.

Con este enfoque, hoy, algunas empresas, empiezan a dar un valor menos central a los accionistas en comparación con otros grupos de interés. Estas compañías están integrando las cuestiones sociales y ambientales en su estrategia de negocio. Las organizaciones que integran voluntariamente las políticas ambientales y sociales en su modelo de negocio representan un tipo fundamentalmente distinto de la empresa, caracterizada por una estructura de gobierno que, además del desempeño financiero, tiene en cuenta el impacto ambiental y social de la empresa. Este enfoque prolongaría al largo plazo las metas de la organización gracias a un proceso activo de gestión de los grupos de interés y sistemas de medición e información más desarrollados que forjarían organizaciones más responsables.

La RSE -o sostenibilidad corporativa según enfoques más recientes (Andreu y Fernández, 2011)-, rompe con el modelo clásico de entender la actividad económica. 
La RSE implica superar el pensamiento único de la dimensión financiera -tomar las decisiones que incrementen los beneficios de accionistas y propietarios- y tener en cuenta en la toma de decisiones a otros grupos de interés. La responsabilidad empresarial o sostenibilidad corporativa es una responsabilidad ante la dimensión no financiera, hacia el medio ambiente, los empleados o las prácticas de buen gobierno corporativo. Es más, muchos autores demuestran que el descuido de estas dimensiones tiene consecuencias financieras (Eccles, Ioannou \& Serafeim, 2014).

A continuación, se expone la cronología de instrumentos internacionales de promoción de la RSE:

\begin{tabular}{|l|l|}
\hline \multicolumn{1}{|c|}{ Iniciativa y fecha } & \multicolumn{1}{c|}{ Concepto } \\
\hline $\begin{array}{l}\text { Declaración tripartita de principios sobre } \\
\text { empresas multinacionales y la política } \\
\text { social de la OIT. Nov } 2000\end{array}$ & $\begin{array}{l}\text { Es el primer documento elaborado exitosa- } \\
\text { mente por la Organización Internacional } \\
\text { del Trabajo (OIT) aplicable universalmente } \\
\text { en materia de empresas multinacionales. } \\
\text { Apunta a alentar la contribución positiva } \\
\text { que las empresas multinacionales ejercen } \\
\text { sobre el progreso económico. }\end{array}$ \\
\hline $\begin{array}{l}\text { Libro verde para fomentar un marco eu- } \\
\text { ropeo para la responsabilidad social de las } \\
\text { empresas de la U.E. Julio de 2001 }\end{array}$ & $\begin{array}{l}\text { Este libro constituye la materialización del } \\
\text { compromiso de la Unión Europea a favor de } \\
\text { la RSC. Mediante un comportamiento so- } \\
\text { cialmente responsable, las empresas pueden } \\
\text { desempeñar un papel esencial para favorecer } \\
\text { que la UE avance hacia su objetivo de mayor } \\
\text { crecimiento económico, competitividad, } \\
\text { justicia social y desarrollo sostenible. }\end{array}$ \\
\hline $\begin{array}{l}\text { Carbon Disclosure Project (CDP) } \\
\text { Leadership Index 2003 }\end{array}$ & $\begin{array}{l}\text { La organización internacional CDP elabora } \\
\text { limate Disclosure Leadership Index } \\
\text { Climate Performance Leadership Index } \\
\text { biental Climate Performabince Leadership Index } \\
\text { (CPLI) y Climate Disclosure Leadership Index } \\
\text { (CDLI), que evalúan el rendimiento y la } \\
\text { divulgación de las empresas en este ámbito. } \\
\text { Las puntuaciones asignadas a las empresas se } \\
\text { basan en respuestas introducidas en el siste- } \\
\text { ma de respuesta en línea del CDP (ORS). }\end{array}$ \\
\hline $\begin{array}{l}\text { ISO 26000 } \\
\text { Septiembre de 2010 }\end{array}$ & $\begin{array}{l}\text { Es la guía que establece las líneas en ma- } \\
\text { teria de responsabilidad social establecidas } \\
\text { por la Organización Internacional para la } \\
\text { Estandarización. Su objetivo principal es } \\
\text { ayudar a las organizaciones a establecer, } \\
\text { implementar, mantener y mejorar los marcos } \\
\text { o estructuras de RS. }\end{array}$ \\
\hline
\end{tabular}




\begin{tabular}{|c|c|}
\hline Iniciativa y fecha & Concepto \\
\hline $\begin{array}{l}\text { Estrategia renovada de la UE para } 2011 \text { - } \\
2014 \text { sobre la responsabilidad social de las } \\
\text { empresas / COM/2011/0681 } \\
\text { Octubre } 2011\end{array}$ & $\begin{array}{l}\text { El principal objetivo del documento es } \\
\text { definir una nueva estrategia para la UE en } \\
\text { materia de RSC. Quizá su logro más impor- } \\
\text { tante sea evolucionar la definición de RSC } \\
\text { y pasar de entenderla como «la integración } \\
\text { voluntaria, por parte de las empresas, de las } \\
\text { preocupaciones sociales y medioambientales } \\
\text { en sus operaciones comerciales y sus rela- } \\
\text { ciones con sus interlocutores», a hablar de } \\
\text { impactos. La nueva definición menciona } \\
\text { que la responsabilidad de las empresas por su } \\
\text { impacto en la sociedad es aquella que, respe- } \\
\text { tando la legislación aplicable en cada estado } \\
\text { miembro, se concreta en dos objetivos: (1) } \\
\text { Maximizar la creación de valor comparti- } \\
\text { do para la sociedad en sentido amplio. Y } \\
\text { (2) Minimizar las consecuencias adversas } \\
\text { mediante la identificación, prevención y } \\
\text { atenuación de las mismas. }\end{array}$ \\
\hline $\begin{array}{l}\text { DIRECTIVA 2014/95/UE DEL PARLA- } \\
\text { MENTO EUROPEO Y DEL CONSEJO } \\
\text { de } 22 \text { de octubre de } 2014 \text { por la que se mo- } \\
\text { difica la Directiva } 2013 / 34 / \text { UE en lo que } \\
\text { respecta a la divulgación de información no } \\
\text { financiera e información sobre diversidad } \\
\text { por parte de determinadas grandes empresas } \\
\text { y determinados grupos } \\
\text { Octubre de } 2014\end{array}$ & $\begin{array}{l}\text { El principal objetivo de esta Directiva es } \\
\text { fijar unas normas comunes para las empresas } \\
\text { en materia de información no financiera. } \\
\text { La Directiva calcula que aproximadamente } \\
6.000 \text { empresas europeas estarán obligadas } \\
\text { a informar en sus reportes anuales infor- } \\
\text { mación relativa a los ámbitos de buen } \\
\text { gobierno, medio ambiente y sociedad. Las } \\
\text { condiciones para que las empresas estén } \\
\text { obligadas a cumplir con esta Directiva es } \\
\text { que sean entidades con un balance total } \\
\text { de } 20 \text { millones de } € \text { o } 40 \text { millones de } € \\
\text { en volumen neto de negocio, con más } \\
\text { de } 500 \text { trabajadores, de interés público y } \\
\text { cuya matriz tenga su sede en un país de la } \\
\text { Unión Europea y/o cotice en alguno de sus } \\
\text { mercados bursátiles. }\end{array}$ \\
\hline
\end{tabular}

Fuente: (Andreu, 2017 y elaboración propia) 
Todos estos progresivos cambios de mentalidad empiezan a hacer de la noción de sostenibilidad una pieza clave de los objetivos de las organizaciones públicas y privadas. Para comprender los orígenes del término es necesario remontarse al Informe Brundtland (1987) que definió desarrollo sostenible "como aquel desarrollo que satisface las necesidades del presente sin comprometer la capacidad de las generaciones futuras de satisfacer sus propias necesidades". Este informe fue el primer instrumento que formaliza la sostenibilidad de forma estructurada. Lleva el apellido de Gro Harlem Brundtland, ex Primera Ministra de Noruega que en aquel tiempo presidía la Comisión Mundial sobre Medio Ambiente y Desarrollo de Naciones Unidas. Desde entonces, el alcance del término sostenibilidad -con un significado orientado hacia el desarrollo ecológico sostenible--, se ha ampliado hacia los factores económicos y sociales (Gladwin, Kennelly y Krause, 1995). Hoy, el objeto de la sostenibilidad es el desarrollo mismo de nuestras sociedades, puesto en entredicho por los impactos sobre el planeta de las actividades económicas. Desde el punto de vista empresarial, la sostenibilidad corporativa debe contribuir positivamente al desarrollo sostenible en lugar de amenazarlo. La empresa sostenible es un modelo de negocio que trasciende el propio ámbito organizativo. Y esto es así porque (debería) forma(r) parte del pensamiento estratégico de la organización.

Bajo nuevos puntos de vista, la interpretación dominante de desarrollo sostenible lleva aparejada los objetivos de justicia, que son el núcleo del principio. La justicia social se convierte así en el contenido básico de una estrategia de sostenibilidad. En tanto interpretación concreta del principio genérico de sostenibilidad, el desarrollo sostenible se fundamenta en el mantenimiento de un nivel de bienestar humano racional, compatible a su vez con el equilibrio ecológico entre la actividad humana y los sistemas naturales (Franco-Barrera, 2018). Como describimos a continuación, estos fundamentos quedan anclados en las convenciones y los pactos internacionales de derechos humanos que son, de hecho, instrumentos vinculantes del derecho internacional. La siguiente tabla muestra la relación de los instrumentos internacionales ligados al medioambiente desde 1972: 


\begin{tabular}{|c|c|}
\hline Iniciativa y fecha & Concepto \\
\hline $\begin{array}{l}\text { Conferencia de las Naciones Unidas } \\
\text { sobre el Medio Humano (1972) }\end{array}$ & $\begin{array}{l}\text { En la resolución } 1346 \text { (XLV) del } 30 \text { de julio } \\
\text { de } 1968 \text {, el Consejo Económico y Social } \\
\text { recomendó a la Asamblea General considerar } \\
\text { la posibilidad de convocar una conferencia } \\
\text { de la ONU para tratar los problemas del } \\
\text { medio ambiente humano. La conferencia } \\
\text { fue convocada por la Asamblea General en } \\
\text { la resolución } 2398 \text { (XXIII) del } 3 \text { de diciembre } \\
\text { de } 1968 \text { y celebrada en Estocolmo del } 5 \text { al } \\
16 \text { de junio de } 1972 \text {. Condujo a la creación } \\
\text { del Programa de las Naciones Unidas para el } \\
\text { Medio Ambiente (PNUMA). }\end{array}$ \\
\hline $\begin{array}{l}\text { Comisión Mundial sobre Medio } \\
\text { Ambiente y Desarrollo (1983) } \\
\text { Resolución 38/181 de } \\
19 \text { de diciembre de } 1983\end{array}$ & $\begin{array}{l}\text { La Asamblea General de la Naciones Uni- } \\
\text { das, crea la Comisión Mundial sobre Medio } \\
\text { Ambiente y Desarrollo como organismo } \\
\text { independiente encargado de: } \\
\text { - Reexaminar y formular propuestas inno- } \\
\text { vadoras, concretas y realistas para afrontar } \\
\text { cuestiones críticas sobre el medioambiente. } \\
\text { - Reforzar y proponer nuevas formas de } \\
\text { cooperación internacional en esa materia. } \\
\text { - Incrementar el conocimiento y compro- } \\
\text { miso de los individuos, las organizaciones } \\
\text { voluntarias, las instituciones y los gobiernos } \\
\text { con el objetivo de un desarrollo sostenible. }\end{array}$ \\
\hline $\begin{array}{l}\text { Confección Informe Brundtland } \\
\text { (1985) }\end{array}$ & $\begin{array}{l}\text { Confección del Informe Nuestro Futuro Común } \\
\text { o Informe Brundtland (Comisión Mundial sobre } \\
\text { Medio Ambiente Desarrollo). } \\
\text { La Comisión Mundial sobre medioambiente } \\
\text { elabora bajo la dirección de la política noruega } \\
\text { Gro Harlem Brundtland el Informe "Nuestro } \\
\text { Futuro Común" en el que se recoge la defi- } \\
\text { nición de desarrollo sostenible entendido } \\
\text { como "aquel que satisface las necesidades } \\
\text { del presente, sin comprometer la capacidad } \\
\text { de las generaciones futuras de satisfacer sus } \\
\text { propias necesidades". }\end{array}$ \\
\hline
\end{tabular}




\begin{tabular}{|c|c|}
\hline Iniciativa y fecha & Concepto \\
\hline $\begin{array}{l}\text { Aprobación Informe Brundtland } \\
\text { (1987) } \\
\text { Decisión 14/14 de } 16 \text { junio } 1987\end{array}$ & $\begin{array}{l}\text { El Informe de la Comisión Mundial sobre } \\
\text { Medioambiente y Desarrollo se presenta a la } \\
\text { Asamblea General de las Naciones Unidas } \\
\text {-Informe Brundtland- junto con un borrador } \\
\text { de recomendaciones para su decisión de con- } \\
\text { sideración y adopción }\end{array}$ \\
\hline $\begin{array}{l}\text { Cumbre de la Tierra o } \\
\text { Conferencia de Río (1988) } \\
\text { Resolución 44/228 de } 20 \text { diciembre } 1988\end{array}$ & $\begin{array}{l}\text { La Asamblea General de la Naciones Unidas } \\
\text { de conformidad con el informe de la Comisión } \\
\text { Mundial convoca la Conferencia de Naciones } \\
\text { Unidas sobre Medio Ambiente y Desarrollo } \\
\text { (Cumbre de la Tierra o Conferencia de Rio), } \\
\text { la cual debería elaborar las estrategias y me- } \\
\text { didas para detener o invertir los efectos de la } \\
\text { degradación del medioambiente }\end{array}$ \\
\hline $\begin{array}{l}\text { Cumbre de Río (1992) } \\
\text { Rio de Janeiro del } 3 \text { al } 14 \text { junio } 1992\end{array}$ & $\begin{array}{l}\text { En la Cumbre de Río se abrieron a la firma } \\
\text { dos instrumentos jurídicamente vinculantes: } \\
\text { - La Convención Marco de las Naciones } \\
\text { Unidas sobre el Cambio Climático. } \\
\text { - El Convenio para la Diversidad Biológica. }\end{array}$ \\
\hline $\begin{array}{l}\text { Declaración de Copenhague (1995) } \\
\text { Copenhague del } 6 \text { a 12, marzo } 1995\end{array}$ & $\begin{array}{l}\text { Cumbre Mundial sobre Desarrollo Social: } \\
\text { Declaración de Copenhague. Los gobiernos } \\
\text { alcanzaron un nuevo consenso sobre la necesi- } \\
\text { dad de asignar a las personas el papel principal } \\
\text { dentro del desarrollo. La Cumbre Social } \\
\text { constituyó la mayor reunión de dirigentes } \\
\text { mundiales hasta el momento que expresaron } \\
\text { su voluntad de considerar la erradicación de } \\
\text { la pobreza, el objetivo del pleno empleo y el } \\
\text { fomento de la integración social como las } \\
\text { metas más importantes del desarrollo. }\end{array}$ \\
\hline $\begin{array}{l}\text { Acuerdo de París (2016) } \\
\text { Adoptado el } 12 \text { de diciembre de } 2015 \text { y } \\
\text { abierto para firma el } 22 \text { de abril de } 2016\end{array}$ & $\begin{array}{l}\text { El Acuerdo de París es un acuerdo dentro de } \\
\text { la Convención Marco de las Naciones Uni- } \\
\text { das sobre el Cambio Climático que establece } \\
\text { medidas para la reducción de las emisiones de } \\
\text { gases de efecto invernadero. Su aplicabilidad } \\
\text { será para el año } 2020 \text {, cuando finaliza la } \\
\text { vigencia del Protocolo de Kioto. El acuerdo } \\
\text { fue negociado durante la XXI Conferencia } \\
\text { sobre Cambio Climático (COP 21) por los }\end{array}$ \\
\hline
\end{tabular}




\begin{tabular}{|l|l|}
\hline Iniciativa y fecha & \multicolumn{1}{|c|}{ Concepto } \\
\hline & 195 países miembros, adoptado el 12 de \\
diciembre de 2015 y abierto para firma el 22 \\
de abril de 2016 para celebrar el Día de la Tierra. \\
Los Gobiernos acordaron el objetivo a largo \\
plazo de mantener el aumento de la temperatura \\
media mundial muy por debajo de $2{ }^{\circ}$ C sobre \\
& los niveles preindustriales, limitar el aumento \\
& a $1,5^{\circ} \mathrm{C}$, lo que reducirá considerablemente los \\
& riesgos y el impacto del cambio climático (si \\
& bien reconocen que en los países en desarrollo \\
& el proceso será más largo) y aplicar rápidas \\
& reducciones basadas en los mejores criterios \\
& científicos disponibles. \\
\hline
\end{tabular}

(Andreu, 2017 y elaboración propia)

La progresiva aparición de toda esta serie de cumbres, acuerdos e instrumentos multilaterales han permitido el lanzamiento, primero de los Objetivos del Milenio, en el año 2000 y, posteriormente, de los Objetivos de Desarrollo Sostenible. Mientras que los Objetivos del Milenio tenían un enfoque social limitado a los países en desarrollo, los Objetivos de Desarrollo Sostenible tienen un enfoque holístico, interconectado o sistémico, que afecta a todos los países. Dentro de ellos, el cambio climático aparece como un eje vertebrador de todos los objetivos por sus consecuencias sistémicas.

Hoy no parece existir ningún campo de la actividad humana que sea inmune al impacto del cambio climático. Las consecuencias de este fenómeno -y el tipo de políticas públicas tomadas para retardarlo o reducirlo- implicarán un cambio en la matriz tecnológica de nuestras sociedades y sus condiciones de vida. La sostenibilidad representa una serie de desafíos para nuestra sociedad global como son el pensamiento a largo plazo, la representación de aquellos que no poseen voz efectiva o la legitimidad de las decisiones -difíciles- que haya que adoptar (Franco-Barrera, 2019a).

En la actualidad, los procesos de digitalización están generando una inmensa cantidad de datos. Toda esta información -y las nuevas técnicas de análisis, por ejemplo, el big data-, pueden ayudar a tomar mejores decisiones para resolver los problemas asociados con la sostenibilidad de las sociedades. Las nuevas técnicas pueden medir con mayor precisión los efectos del cambio climático, prevenir los riesgos de inundación o controlar la difusión de enfermedades. El análisis de grandes datos puede generar planes de acción más eficientes frente a catástrofes futuras. Por todo ello entendemos que es clave estudiar el impacto de la tecnología en cada uno de los ODS. 


\section{LA TECNOLOGÍA: UN ELEMENTO CENTRAL PARA LA AGENDA 2030}

En el siglo XIX, el motor de vapor, la locomotora y las infraestructuras ferroviarias marcaron el inicio de la era del carbón, la primera revolución industrial. El motor de combustión interna y las infraestructuras de transporte definieron la segunda revolución industrial en el siglo XX, la era del petróleo. En el siglo XXI, el suministro de energía que ofrece el petróleo, el carbón y el gas natural se reducirá. Nos encontramos en el final de la era de los combustibles fósiles, tanto por la amenaza del cambio climático como por el cénit global de la producción de petróleo.

Como consecuencia, se generan dos procesos. Por una parte, el uso cada vez más eficiente de los combustibles restantes. Por otra, la sustitución de los combustibles convencionales por tecnologías "limpias". Para Jeremy Rifkin (2010), el uso de las tecnologías de la información y las comunicaciones como mecanismo de control para organizar y administrar una nueva distribución de la energía marca el comienzo de la tercera revolución industrial. Las energías distributivas son aquellas que se encuentran en todas partes, mientras que las energías convencionales se encuentran en regiones geográficas concretas. Al mismo tiempo que los gobiernos imponen nuevas formas de regulación y establecen objetivos temporales para su introducción en el mercado, los costes de estas energías se reducen gracias a la investigación, aumentando su carácter competitivo. Para Rifkin, el pequeño porcentaje del mix energético global actual aumentará, reduciéndose el porcentaje de las energías convencionales. Finalmente, una red interconectada inteligente generará una mayor eficiencia energética en la distribución de la electricidad.

La revolución en las infraestructuras de transporte que definieron las dos primeras revoluciones (ferrocarril y carreteras, respectivamente) exigen de igual forma una infraestructura equivalente para la tercera revolución industrial. La transición a la tercera revolución industrial supondrá la reconversión de la infraestructura económica de los países con la aparición de nuevas estaciones de recarga para vehículos eléctricos:

"Los países tendrán que realizar inversiones masivas en energías renovables, reconvertir millones de edificios para transformarlos en plantas productoras de energía, incluir la tecnología del hidrógeno y otras tecnologías de almacenamiento en todas las infraestructuras nacionales, transformar el automóvil de motor de combustión interna en coches eléctricos y vehículos que funcionen con células de combustible, y crear una red eléctrica inteligente" (Rifkin, 2010, p. 514).

Sin embargo, para Klaus Schwab (2016), estamos viviendo el comienzo de una revolución económica y social profunda con importantes consecuencias en la 
distribución del poder, la riqueza y el conocimiento. Es la Cuarta Revolución Industrial, que se caracteriza por la existencia de máquinas y sistemas interconectados de forma permanente en todo el proceso productivo. Para Schwab, la primera revolución industrial utilizó la energía del agua y del vapor para mecanizar la producción. La segunda utilizó la energía eléctrica para crear la producción en masa. La tercera utilizó la electrónica y la tecnología de la información para automatizar la producción. Ahora una cuarta revolución industrial se está construyendo sobre la tercera, la revolución digital que ha estado ocurriendo desde mediados del siglo pasado.

La cuarta revolución industrial es diferente a la tercera por tres aspectos fundamentales. En primer lugar, por la velocidad, que no tiene precedentes históricos y evoluciona a un ritmo exponencial. En segundo lugar, por el alcance y la profundidad, no sólo se está cambiando el funcionamiento de los procesos, sino que dichos cambios afectan a nuestra subjetividad. En tercer lugar, por el impacto en los sistemas; se trata de una transformación sistémica que afecta a países, industrias y la sociedad en su conjunto.

La Industria 4.0 es un término acuñado en la Feria de Hannover de 2011 para describir cómo la tecnología revolucionará la organización de las cadenas de valor globales. Mediante la creación de fábricas inteligentes, la cuarta revolución industrial genera un mundo en el que sistemas de fabricación virtuales y físicos cooperan entre sí de una manera flexible en todo el planeta. Esto permite la personalización de los productos y la creación de nuevos modelos de conocimiento del entorno.

Tecnologías como la robótica, la inteligencia artificial, el blockchain, el big data, el internet de las cosas, la impresión 3D, los vehículos autónomos, la nanotecnología, la biotecnología o la computación cuántica forman parte del nuevo ecosistema tecnológico. Este mundo interconectado -tanto a nivel digital como al nivel de las cosas-, es un mundo automatizado que permite resolver con mayor facilidad tanto los problemas de las organizaciones como los de la vida cotidiana.

Desde que se inició la era digital con la puesta en marcha de los primeros computadores, la digitalización no ha cesado de avanzar a unos ritmos que han sobrepasado las previsiones más optimistas y, ahora mismo, nada indica que se vaya a interrumpir ese ritmo de cambio. Incluso se puede acelerar. La revolución que ha dado origen a la era digital está cambiando casi todo: cómo nos comunicamos, cómo vivimos, cómo se trabaja, cómo se organizan las empresas. En el pasado las tecnologías digitales eran herramientas utilizadas por las organizaciones para actividades concretas o particulares. Hoy son la columna vertebral de las organizaciones y la mayoría de los procesos de la organización involucran actividades digitales. Los procesos de digitalización y de creación de grandes bases de datos crean condiciones novedosas para las organizaciones; aparecen nuevas cuestiones como el tratamiento de datos, nuevos modos de producción, problemas sociales y, por supuesto, nuevas formas de gobierno corporativo. 
Las agendas globales impulsadas por Naciones Unidas contribuyen a que hoy el mundo tenga los mejores indicadores de desarrollo de la historia. Sin embargo, los ODS corren el riesgo de perder una enorme oportunidad: la de apoyarse en la tecnología y en la revolución digital para acelerar la mejora de las condiciones de vida de la población y la sostenibilidad del planeta. A pesar de ello, como veremos, en la práctica, la revolución digital está logrando ser el catalizador de los distintos ODS (Andreu \& Fernández, 2019). Desde el punto de vista más teórico, la innovación figura como un apéndice en el objetivo 9 , dedicado a Construir infraestructuras resilientes, promover la industrialización inclusiva y sostenible y fomentar la innovación. En términos estratégicos, la innovación figura exclusivamente como un "vertical" en el objetivo 9 y no como un "trasversal" con la capacidad de impactar en todos los objetivos restantes. En otras palabras: mientras que la revolución digital es imparable, los ODS incorporan la innovación y la tecnología como un objetivo más, no como el motor de todos ellos. Este carácter limitado (ODS 9) o genérico (ODS 17) de la tecnología en la Agenda, jes debido a las posibles limitaciones de la propia tecnología? Esta hipótesis contribuye a estructurar en gran medida este trabajo: los aspectos catalizadores e inhibidores de la tecnología en la Agenda 2030.

El impacto de la tecnología puede ser masivo para la educación, el agua, la energía, el trabajo, la producción, la lucha contra el cambio climático, la vida submarina, la transparencia, la reducción del hambre o la pobreza. Como se pone de manifiesto en el informe Global Opportunity Report de 2018, la clave es la intersección entre tecnología y empresa (DNV-GL, 2018). La gran mayoría de las 55 oportunidades que define el informe emplean innovaciones tecnológicas, pero la digitalización de ciertos productos y servicios puede no ser suficiente para seguir siendo competitivo. La tecnología no solo mejora las condiciones de vida de las personas, sino que también genera nuevos motores de crecimiento económico sostenible:

- En salud, el internet de las personas (utilizando las tecnologías móviles en la atención sanitaria) está abriendo nuevas oportunidades para prestar asistencia sanitaria a comunidades remotas de bajos ingresos a través de soluciones móviles.

- En alimentación, avances tecnológicos como la agricultura por goteo y el acceso a datos meteorológicos en tiempo real están ayudando tanto a los grandes como a los pequeños agricultores, que producen más con menos.

- En recursos hídricos, la innovadora tecnología de sensores y las redes inteligentes permiten a las ciudades gestionar sus suministros de agua de forma más eficiente y evitar interrupciones en la prestación de servicios.

- En energía, reutilizar las baterías puede ayudar a descarbonizar el sistema energético, donde una creciente dependencia de las energías renovables requiere de una mayor flexibilidad en el almacenamiento de energía. 
Podríamos poner cientos de ejemplos de cómo la tecnología impacta en cada uno de los 17 objetivos de desarrollo sostenible. A continuación, mencionaremos algunos de los más representativos, ejemplificando también los límites de la tecnología. Esto es así porque, si bien la tecnología es un importante catalizador de la Agenda 2030, también existen inhibidores sistémicos que pueden limitar sus efectos y, por tanto, la consecución de las correspondientes metas. Además, ejemplificaremos la protección de los ODS en los correspondientes instrumentos jurídicos internacionales haciendo uso de la guía del Instituto Danés de Derechos Humanos. Los instrumentos de derechos humanos y la Agenda 2030 están ligados y se refuerzan mutuamente: los derechos humanos ofrecen un marco legalmente vinculante y los ODS pueden contribuir sustancialmente a la realización de los derechos humanos.

\section{LAS OPORTUNIDADES Y LIMITACIONES TECNOLÓGICAS PARA POTENCIAR LOS ODS}

La metodología del siguiente estudio consiste en identificar qué metas de los ODS podrían verse potenciadas por la tecnología, que cumpliría una función catalizadora. En gris se exponen los límites que pueden generar las propias tecnologías o las dificultades sistémicas dado el carácter holístico de los ODS. En este caso, ciertos elementos o procesos -no necesariamente tecnológicos- podrían actuar de inhibidores. El último cuadro de cada ODS establece qué derechos y acuerdos podrían verse afectados por la consecución (o no) de los ODS.

\section{OBJETIVO DE DESARROLLO SOSTENIBLE 1: PONER FIN A LA POBREZA EN TODAS SUS FORMAS EN TODO EL MUNDO}

Dentro del ODS 1, la meta 1.A pide "garantizar una movilización importante de recursos procedentes de diversas fuentes, incluso mediante la mejora de la cooperación para el desarrollo, a fin de proporcionar medios suficientes y previsibles a los países en desarrollo, en particular los países menos adelantados, para poner en práctica programas y políticas encaminados a poner fin a la pobreza en todas sus dimensiones". Con el objetivo de erradicar la pobreza, por ejemplo, el departamento de economía de MIT ha impulsado varios centros de investigación. En concreto, el Abdul Latif Jameel Poverty Action Lab (J-PAL), una red de profesores afiliados de todo el mundo que están unidos en el uso de las evaluaciones aleatorias para responder preguntas fundamentales para reducir la pobreza. Su objetivo es reducir la pobreza al asegurar que la política se basa en la evidencia científica, colaborando con gobiernos, ONG y organizaciones internacionales para el desarrollo de programas ampliados de probada eficacia, respaldando la política en el mundo en desarrollo (Zhang, 2014). Abhijit Banerjee y Esther Duflo, creadores del centro, han recibido el Premio Nobel de Economía en 2019. 
El estudio de Diffenbaugh y Burke (2019) titulado Global warming has increased global economic inequality demuestra que el calentamiento global ha exacerbado la desigualdad económica global. Este aumento es el resultado del impacto del cambio climático en el crecimiento económico anual, que a lo largo de décadas ha acumulado disminuciones robustas y sustanciales de la producción económica en países más cálidos y pobres, y aumentos en muchos países más fríos y ricos, en relación con un mundo sin calentamiento antropogénico. Por lo tanto, el calentamiento global causado por el uso de combustibles fósiles probablemente ha exacerbado la desigualdad económica asociada con las disparidades históricas en el consumo de energía. El ODS 1, en particular la meta 1.5 plantea De aquí a 2030, fomentar la resiliencia de los pobres y las personas que se encuentran en situaciones de vulnerabilidad y reducir su exposición y vulnerabilidad a los fenómenos extremos relacionados con el clima y otras perturbaciones y desastres económicos, sociales y ambientales. El cambio climático puede limitar los intentos por corregir la desigualdad económica y, por tanto, dificultar la lucha contra la pobreza.

\begin{tabular}{|l|l|}
\hline \multicolumn{1}{|c|}{ Acuerdos y derechos afectados } \\
\hline \multicolumn{1}{|c|}{ Instrumento } & \multicolumn{1}{c|}{ Artículo } \\
\hline declaración universal de los humanos & $\begin{array}{l}\text { 3. Todo individuo tiene derecho a la vida, a la libertad y a la } \\
\text { seguridad de su persona. }\end{array}$ \\
\hline $\begin{array}{l}\text { Convención Marco de las } \\
\text { Cambiones Unidas sobre el }\end{array}$ & $\begin{array}{l}\text { 3.4. Las Partes tienen derecho al desarrollo sostenible y de- } \\
\text { berían promoverlo. Las políticas y medidas para proteger el } \\
\text { sistema climático contra el cambio inducido por el ser humano } \\
\text { deberían ser apropiadas para las condiciones específicas de } \\
\text { cada una de las Partes y estar integradas en los programas } \\
\text { nacionales de desarrollo, teniendo en cuenta que el creci- } \\
\text { miento económico es esencial para la adopción de medidas } \\
\text { encaminadas a hacer frente al cambio climático. }\end{array}$ \\
\hline Acuerdo de París & $\begin{array}{l}\text { 4.1. Para cumplir el objetivo a largo plazo referente a la } \\
\text { temperatura que se establece en el artículo 2, las Partes se } \\
\text { proponen lograr que las emisiones mundiales de gases de efecto } \\
\text { invernadero alcancen su punto máximo lo antes posible, } \\
\text { teniendo presente que las Partes que son países en desarrollo } \\
\text { tardarán más en lograrlo, y a partir de ese momento reducir } \\
\text { rápidamente las emisiones de gases de efecto invernadero, de } \\
\text { conformidad con la mejor información científica disponible, } \\
\text { para alcanzar un equilibrio entre las emisiones antropógenas } \\
\text { por las fuentes y la absorción antropógena por los sumideros } \\
\text { en la segunda mitad del siglo, sobre la base de la equidad y } \\
\text { en el contexto del desarrollo sostenible y de los esfuerzos por } \\
\text { erradicar la pobreza }\end{array}$ \\
\hline
\end{tabular}

UDHR (1948), UNFCCC (1992), UNFCCC (2015) 
2. OBJETIVO DE DESARROLLO SOSTENIBLE 2: PONER FIN AL HAMBRE, LOGRAR LA SEGURIDAD ALIMENTARIA Y LA MEJORA DE LA NUTRICIÓN Y PROMOVER LA AGRICULTURA SOSTENIBLE

Dentro del ODS 2, la meta 2.4 plantea, para 2030, "asegurar la sostenibilidad de los sistemas de producción de alimentos y aplicar prácticas agrícolas resilientes que aumenten la productividad y la producción, contribuyan al mantenimiento de los ecosistemas, fortalezcan la capacidad de adaptación al cambio climático, los fenómenos meteorológicos extremos, las sequías, las inundaciones y otros desastres, y mejoren progresivamente la calidad del suelo y la tierra".

El interés en la agricultura vertical cobró fuerza tras la publicación del libro de Despommier (2010), The Vertical Farm: Feeding the World in the 21st Century, que argumentaba que los beneficios de la agricultura en invernadero en interiores podrían multiplicarse en gran medida si se construían edificios de gran altura en entornos urbanos. La agricultura vertical se basa en el cultivo por aeroponía, una tecnología que no requiere tierra, ni sol ni agua: consiste en rociar las raíces de las plantas con soluciones nutritivas atomizadas o nieblas (Christie \& Nichols, 2004). Puesto que las plantas no absorben el agua de la tierra, el nivel de oxígeno aumenta, haciendo que el crecimiento sea más sano y más rápido. Si con el cultivo tradicional los vegetales crecen en unos 30 días, con este método innovador lo hacen en 16. Si a esto le añadimos que se trata de un método que consume un 95\% menos de agua que los métodos agrícolas tradicionales -y que no requiere el uso de pesticidas ni herbicidas- la agricultura vertical se perfila como la alternativa perfecta (Gómez-Cotta, 2019).

Un buen ejemplo de la aplicación de esta tecnología en la producción está en Singapur, donde viven más de cinco millones de personas hacinadas en un área de 700 kilómetros cuadrados. La empresa Sky Greens y su tecnología "A-Go-Gro" genera rendimientos significativamente más altos que los métodos de cultivo tradicionales. Mediante sus estanterías de aluminio produce cultivos seguros, de alta calidad y frescos, cultivándose grandes variedades de vegetales como el repollo chino, espinacas, lechuga, o coles (Krishnamurthy, 2014).

Los beneficios potenciales de la agricultura vertical incluyen un modelo sostenible de producción de alimentos con producción de cultivos durante todo el año, mayores rendimientos en un orden de magnitud y ausencia de sequías, inundaciones y plagas. El enfoque es compatible con el reciclaje del agua, la restauración del ecosistema, la reducción de patógenos, la producción de energía mediante la generación de metano a partir de compost, la disminución del uso de combustibles fósiles ( $\sin$ tractores, arados ni embarcaciones), la generación de 
nuevos empleos durante muchos años y la baja o nula necesidad de plaguicidas (Benke \& Tomkins, 2017).

La meta 2.5.a plantea "aumentar las inversiones, incluso mediante una mayor cooperación internacional, en la infraestructura rural, la investigación agrícola y los servicios de extensión, el desarrollo tecnológico y los bancos de genes de plantas y ganado a fin de mejorar la capacidad de producción agrícola en los países en desarrollo, en particular en los países menos adelantados".

Aquí las tecnologías de la cuarta revolución industrial pueden jugar un importante papel para potenciar la agricultura sostenible vía desarrollo tecnológico e infraestructura rural. El blockchain permite a las personas llegar a acuerdos de persona a persona, pasando por alto la política y la burocracia. Los agricultores, ganaderos, distribuidores y organizaciones que se preocupan por el medio ambiente deben poder colaborar directamente gracias a la cadena de bloques. Los gobiernos, las organizaciones sin ánimo de lucro y las empresas que quieran promover la agricultura regenerativa pueden pagar a los agricultores por el cuidado de los ecosistemas, como los cultivos de cobertura, la plantación de árboles y el mantenimiento del suelo.

La verificación del estado de las tierras es un proceso lento, burocrático y costoso, y a menudo los agricultores tardan años en recibir recompensas. Utilizando una combinación de tecnologías como la inteligencia artificial, sistemas de monitoreo y detección como satélites y sensores terrestres, y el blockchain, Regen Network tiene como objetivo proporcionar una imagen global del estado de los sistemas agrícolas, proporcionando incentivos para la regeneración a través de la visualización de paisajes degradados. El 37\% de la superficie de la Tierra se utiliza para la agricultura, por lo que la empresa ha focalizado su atención en los agricultores como agentes de cambio. Los usuarios pueden introducir datos sobre el estado del ecosistema a un sistema de blockchain, y luego compartir o vender esos datos con otros usuarios de la red. Mediante smart contracts pueden pagar a los agricultores por las prácticas regenerativas, de acuerdo con una serie de protocolos ecológicos desarrollados en colaboración por los usuarios de la red y los científicos (Politano, 2018). 
De acuerdo con el Panel Intergubernamental del Cambio Climático (IPCC, 2007), los combustibles fósiles, el uso de tierras, y la agricultura, son las tres causas principales del incremento de los gases de efecto invernadero desde hace 250 años. El cambio climático y la agricultura son procesos relacionados entre sí que tienen efecto a escala mundial. El cambio climático afecta a la agricultura de diferentes maneras, por medio de cambios en la temperatura promedio, las precipitaciones, y los climas extremos (como olas de calor). El cambio climático ya está afectando a la agricultura, de manera desigual a lo largo del mundo. En el futuro, se prevé que el cambio climático afecte negativamente a los cultivos en países de baja altitud. El cambio climático incrementará el riesgo de seguridad alimentaria para las poblaciones vulnerables.

\begin{tabular}{|l|l|}
\hline \multicolumn{1}{|c|}{ Instrumento } & \multicolumn{1}{c|}{ Acuerdos y derechos afectados } \\
\hline $\begin{array}{l}\text { Convención Marco de las } \\
\text { Naciones Unidas sobre el } \\
\text { Cambio Climático }\end{array}$ & $\begin{array}{l}\text { 4.1 Todas las Partes, teniendo en cuenta sus responsabilidades } \\
\text { comunes pero diferenciadas y el carácter específico de sus } \\
\text { prioridades nacionales y regionales de desarrollo, de sus objetivos } \\
\text { y de sus circunstancias, deberán: } \\
\text { 4.1.c Promover y apoyar con su cooperación el desarrollo, la } \\
\text { aplicación y la difusión, incluida la transferencia, de tecnologías, } \\
\text { prácticas y procesos que controlen, reduzcan o prevengan las } \\
\text { emisiones antropógenas de gases de efecto invernadero no } \\
\text { controlados por el Protocolo de Montreal en todos los sectores } \\
\text { pertinentes, entre ellos la energía, el transporte, la industria, la } \\
\text { agricultura, la silvicultura y la gestión de desechos }\end{array}$ \\
\hline Acuerdo de París & $\begin{array}{l}\text { 7.2 Las Partes reconocen que la adaptación es un desafío mundial } \\
\text { que incumbe a todos, con dimensiones locales, subnacionales, } \\
\text { nacionales, regionales e internacionales, y que es un componente } \\
\text { fundamental de la respuesta mundial a largo plazo frente al } \\
\text { cambio climático y contribuye a esa respuesta, cuyo fin es } \\
\text { proteger a las personas, los medios de vida y los ecosistemas, } \\
\text { teniendo en cuenta las necesidades urgentes e inmediatas de las } \\
\text { Partes que son países en desarrollo particularmente vulnerables } \\
\text { a los efectos adversos del cambio climático. }\end{array}$ \\
\hline
\end{tabular}

UNFCCC (1992), UNFCCC (2015) 


\section{OBJETIVO DE DESARROLLO SOSTENIBLE 3: GARANTIZAR UNA VIDA SANA Y PROMOVER EL BIENESTAR PARA TODOS EN TODAS LAS EDADES}

Dentro del ODS 3, la meta 3.9.d pide "reforzar la capacidad de todos los países, en particular los países en desarrollo, en materia de alerta temprana, reducción de riesgos y gestión de los riesgos para la salud nacional y mundial”. En salud, el ejemplo de Watson, el programa de inteligencia artificial de IBM, está revolucionando el campo del diagnóstico médico. Con el análisis de más de 600.000 piezas de evidencias médicas, de más de dos millones de páginas de revistas médicas y la capacidad adicional para buscar a través de hasta 1,5 millones de registros de pacientes, Watson dispone de más información que ningún "médico humano" para formular diagnósticos (Steadman, 2013). Los resultados son definitivos: en las pruebas, el acierto en el diagnóstico en el cáncer de pulmón es del 90\%, frente al 50\% de los mejores "médicos humanos".

Otro ejemplo de aplicación de la tecnología para la mejora de la salud ha sido desarrollado por los investigadores del Instituto de Tecnología de Israel (Technion) y la Escuela Politécnica Federal de Zúrich, que están diseñando nanobots fabricados con polímeros y nanocables magnéticos, creados para ser introducidos en el torrente sanguíneo humano y teledirigidos en su interior para detectar células cancerígenas y liberar medicamentos sobre ellas (Jang et al., 2015).

Si leemos en detalle el ODS 3, veremos que se centra en regiones que se enfrentan a graves riesgos para la salud, como altas tasas de mortalidad materna y neonatal, la propagación de enfermedades infecciosas y no transmisibles y una mala salud reproductiva. Lo vemos en la meta 3.1 Para 2030, reducir la tasa mundial de mortalidad materna a menos de 70 por cada 100.000 nacidos vivos y 3.2, De aquí a 2030, poner fin a las muertes evitables de recién nacidos y de niños menores de 5 años. Sin embargo, estos objetivos serían poco ambiciosos para los países más desarrollados, en los que, debido a sus sistemas de salud, ya se está pensando más en revisar y valorar algunas de las nuevas posturas filosóficas que buscan perfeccionar al ser humano mediante la tecnología: hablamos del transhumanismo (Andreu y Fernández, 2019, 11 de octubre). El humanismo tiende a basarse exclusivamente en el refinamiento educativo y cultural para mejorar la naturaleza humana, mientras que los transhumanistas quieren aplicar la tecnología para superar los límites impuestos por nuestro patrimonio biológico y genético. Las nuevas tecnologías médicas dirigidas a mejorar el diagnóstico médico y aumentar la esperanza de vida humana tendrían unos beneficiarios: los ciudadanos más pudientes. Por tanto, estas tecnologías dirigidas a mejorar la salud, el bienestar y, en definitiva, la felicidad, pudieran tener un efecto negativo en el ODS 10 (reducción de las desigualdades). 


\begin{tabular}{|l|l|}
\hline \multicolumn{1}{|c|}{ Instrumento } & \multicolumn{1}{c|}{ Acuerdos y derechos afectados } \\
\hline $\begin{array}{l}\text { Declaración universal de } \\
\text { los derechos humanos }\end{array}$ & $\begin{array}{l}\text { 3. Todo individuo tiene derecho a la vida, a la libertad y a la } \\
\text { seguridad de su persona. } \\
\text { 25.1 Toda persona tiene derecho a un nivel de vida adecuado } \\
\text { que le asegure, así como a su familia, la salud y el bienestar, y } \\
\text { en especial la alimentación, el vestido, la vivienda, la asistencia } \\
\text { médica y los servicios sociales necesarios; tiene asimismo } \\
\text { derecho a los seguros en caso de desempleo, enfermedad, } \\
\text { invalidez, viudez, vejez y otros casos de pérdida de sus medios de } \\
\text { subsistencia por circunstancias independientes de su voluntad. }\end{array}$ \\
\hline $\begin{array}{l}\text { Convención sobre los } \\
\text { derechos del niño }\end{array}$ & $\begin{array}{l}\text { 24.1 Los Estados Partes reconocen el derecho del niño al } \\
\text { disfrute del más alto nivel posible de salud y a servicios para } \\
\text { el tratamiento de las enfermedades y la rehabilitación de } \\
\text { la salud. Los Estados Partes se esforzarán por asegurar que } \\
\text { ningún niño sea privado de su derecho al disfrute de esos } \\
\text { servicios sanitarios. }\end{array}$ \\
\hline $\begin{array}{l}\text { Convención sobre la } \\
\text { eliminación de todas las } \\
\text { formas de discriminación } \\
\text { contra la mujer }\end{array}$ & $\begin{array}{l}\text { 12.1 Los Estados Partes adoptarán todas las medidas apropiadas } \\
\text { para eliminar la discriminación contra la mujer en la esfera } \\
\text { de la atención médica a fin de asegurar, en condiciones de } \\
\text { igualdad entre hombres y mujeres, el acceso a servicios de } \\
\text { atención médica, inclusive los que se refieren a la planificación } \\
\text { de la familia. } \\
\text { 12.2 Sin perjuicio de lo dispuesto en el párrafo 1 supra, los } \\
\text { Estados Partes garantizarán a la mujer servicios apropiados } \\
\text { en relación con el embarazo, el parto y el período posterior } \\
\text { al parto, proporcionando servicios gratuitos cuando fuere } \\
\text { necesario, y le asegurarán una nutrición adecuada durante } \\
\text { el embarazo y la lactancia. }\end{array}$ \\
\hline
\end{tabular}

UDHR (1948), CEDAW (1979), UNCRC (1989). 


\section{OBJETIVO DE DESARROLLO SOSTENIBLE 4: GARANTIZAR UNA EDUCACIÓN INCLUSIVA, EQUITATIVA Y DE CALIDAD Y PROMOVER OPORTUNIDADES DE APRENDIZAJE DURANTE TODA LA VIDA PARA TODOS}

La educación es otro de los campos donde la tecnología puede acelerar el desarrollo. Según el Informe de Seguimiento de la Educación en el Mundo (2016), elaborado por la UNESCO, 263 millones de niños, adolescentes y jóvenes estaban sin escolarizar. Dos proyectos destacados se proponen paliar este déficit haciendo uso de la educación digital. Uno de ellos es el proyecto Profuturo, de Fundación Telefónica y Fundación La Caixa. Ambas entidades impulsan de forma conjunta el programa Profuturo, de educación digital en niños de entornos vulnerables de América Latina, Asia y África (OECD, 2018). Desde su creación en 2016, se ha extendido a más de 2.800 escuelas en 26 países. Al cierre del 2018, casi cuatro millones de niños se habían beneficiado de este proyecto.

Otro caso famoso es la Khan Academy, una organización de aprendizaje electrónico en línea, basada en donaciones con un modelo muy similar a la Wikipedia. Con ella se puede estudiar gratuitamente sobre matemáticas, arte, programación, economía, física, química, biología, medicina, finanzas, historia, etc. Su misión: proporcionar una educación gratuita de nivel mundial para cualquier persona, en cualquier lugar (Thompson, 2011). Este acceso al conocimiento puede permitir lograr la meta 4.7, De aquí a 2030, asegurar que todos los alumnos adquieran los conocimientos teóricos y prácticos necesarios para promover el desarrollo sostenible, entre otras cosas mediante la educación para el desarrollo sostenible y los estilos de vida sostenibles, los derechos humanos, la igualdad de género, la promoción de una cultura de paz y no violencia, la ciudadanía mundial y la valoración de la diversidad cultural y la contribución de la cultura al desarrollo sostenible.

Las nuevas empresas tecnológicas están empezando a acumular riqueza, lo que claramente incrementa las desigualdades, en contra de lo que persigue el ODS 10. Como consecuencia de estos cambios, los medios económicos para la instrucción técnica y profesional, clave en una sociedad basada en la tecnología, pueden quedar peor distribuidos y dificultar el acceso al trabajo por la ausencia de formación y conocimiento. Esto dificultaría la consecución de las metas 4.3 De aquí a 2030, asegurar el acceso igualitario de todos los hombres y las mujeres a una formación técnica, profesional y superior de calidad, incluida la enseñanza universitaria y 4.4 De aqui a 2030, aumentar considerablemente el número de jóvenes y adultos que tienen las competencias necesarias, en particular técnicas y profesionales, para acceder al empleo, el trabajo decente y el emprendimiento. Como vemos los ODS 4, 8 y 10 se retroalimentan. 


\begin{tabular}{|l|l|}
\hline \multicolumn{1}{|c|}{ Acuerdos y derechos afectados } \\
\hline \multicolumn{1}{|c|}{ Instrumento } & \multicolumn{1}{c|}{ Artículo } \\
\hline los derechos humanos & $\begin{array}{l}\text { 26.1 Toda persona tiene derecho a la educación. La educación } \\
\text { debe ser gratuita, al menos en lo concerniente a la instruc- } \\
\text { ción elemental y fundamental. La instrucción elemental será } \\
\text { obligatoria. La instrucción técnica y profesional habrá de ser } \\
\text { generalizada; el acceso a los estudios superiores será igual para } \\
\text { todos, en función de los méritos respectivos. } \\
\text { 26.2 La educación tendrá por objeto el pleno desarrollo de } \\
\text { la personalidad humana y el fortalecimiento del respeto a los } \\
\text { derechos humanos y a las libertades fundamentales; favorece- } \\
\text { rá la comprensión, la tolerancia y la amistad entre todas las } \\
\text { naciones y todos los grupos étnicos o religiosos; y promoverá } \\
\text { el desarrollo de las actividades de las Naciones Unidas para el } \\
\text { mantenimiento de la paz. }\end{array}$ \\
\hline Acuerdo de París & $\begin{array}{l}\text { 12. Las Partes deberán cooperar en la adopción de las medidas } \\
\text { que correspondan para mejorar la educación, la formación, la } \\
\text { sensibilización y participación del público y el acceso público } \\
\text { a la información sobre el cambio climático, teniendo presente } \\
\text { la importancia de estas medidas para mejorar la acción en el } \\
\text { marco del presente Acuerdo. }\end{array}$ \\
\hline
\end{tabular}

UDHR (1948), UNFCCC (2015)

\section{OBJETIVO DE DESARROLLO SOSTENIBLE 5: LOGRAR LA IGUALDAD ENTRE LOS GÉNEROS Y EMPODERAR A TODAS LAS MUJERES Y LAS NIÑAS}

Joy Adowaa Buolamwini, una informática y activista digital ghana-estadounidense que trabaja para en el MIT Media Lab, fundó la Algorithmic Justice League para denunciar los sesgos raciales y de género. Su trabajo de investigación, junto con el de Timnit Gebru (2018), puso a prueba los sistemas de reconocimiento facial disponibles concluyendo que las mujeres racializadas eran infrarrepresentadas en estos sistemas de inteligencia artificial. Gracias a su esfuerzo, grandes compañías tecnológicas como IBM y Microsoft han tenido que modificar sus sistemas de software. Este es un ejemplo de cómo la tecnología, utilizada de forma crítica, puede potenciar la igualdad de género. 
Todas las personas tienen una comprensión predeterminada de su entorno, es una condición cultural para entender la realidad, pero también puede ser un límite por la existencia de prejuicios. Los sesgos de género pueden ser replicados en los sistemas de inteligencia artificial generando una desigualdad que impide lograr la primera de las metas del ODS 5, Poner fin a todas las formas de discriminación contra todas las mujeres y las niñas en todo el mundo. La meta 5.6.b llama a mejorar el uso de la tecnología instrumental, en particular la tecnología de la información y las comunicaciones, para promover el empoderamiento de las mujeres.

\begin{tabular}{|c|c|}
\hline \multicolumn{2}{|r|}{ Acuerdos y derechos afectados } \\
\hline Instrumento & Artículo \\
\hline $\begin{array}{l}\text { Convención sobre } \\
\text { la eliminación de } \\
\text { todas las formas } \\
\text { de discriminación } \\
\text { contra la mujer }\end{array}$ & $\begin{array}{l}\text { 2. Los Estados Partes condenan la discriminación contra la mujer en } \\
\text { todas sus formas, convienen en seguir, por todos los medios apropiados } \\
\text { y sin dilaciones, una política encaminada a eliminar la discriminación } \\
\text { contra la mujer y, con tal objeto, se comprometen a: } \\
\text { 2.a Consagrar, si aún no lo han hecho, en sus constituciones nacionales } \\
\text { y en cualquier otra legislación apropiada el principio de la igualdad } \\
\text { del hombre y de la mujer y asegurar por ley u otros medios apropiados } \\
\text { la realización práctica de ese principio. } \\
\text { 2.b Adoptar medidas adecuadas, legislativas y de otro carácter, con } \\
\text { las sanciones correspondientes, que prohíban toda discriminación } \\
\text { contra la mujer. } \\
\text { 2.c Establecer la protección jurídica de los derechos de la mujer sobre } \\
\text { una base de igualdad con los del hombre y garantizar, por conducto de } \\
\text { los tribunales nacionales competentes y de otras instituciones públicas, } \\
\text { la protección efectiva de la mujer contra todo acto de discriminación. } \\
\text { 2.f Adoptar todas las medidas adecuadas, incluso de carácter legislativo, } \\
\text { para modificar o derogar leyes, reglamentos, usos y prácticas que } \\
\text { constituyan discriminación contra la mujer. } \\
\text { 3. Los Estados Partes tomarán en todas las esferas, y en particular en } \\
\text { las esferas política, social, económica y cultural, todas las medidas } \\
\text { apropiadas, incluso de carácter legislativo, para asegurar el pleno desa- } \\
\text { rrollo y adelanto de la mujer, con el objeto de garantizarle el ejercicio } \\
\text { y el goce de los derechos humanos y las libertades fundamentales en } \\
\text { igualdad de condiciones con el hombre. }\end{array}$ \\
\hline $\begin{array}{l}\text { Declaración sobre } \\
\text { la eliminación de la } \\
\text { violencia contra la } \\
\text { mujer }\end{array}$ & $\begin{array}{l}\text { 4. Los Estados deben condenar la violencia contra la mujer y no invocar } \\
\text { ninguna costumbre, tradición o consideración religiosa para eludir su } \\
\text { obligación de procurar eliminarla. Los Estados deben aplicar por todos } \\
\text { los medios apropiados y sin demora una política encaminada a eliminar } \\
\text { la violencia contra la mujer. Con este fin, deberán: } \\
\text { 4.f Elaborar, con carácter general, enfoques de tipo preventivo } \\
\text { y todas las medidas de índole jurídica, política, administrativa y } \\
\text { cultural que puedan fomentar la protección de la mujer contra } \\
\text { toda forma de violencia, y evitar eficazmente la reincidencia en la } \\
\text { victimización de la mujer como consecuencia de leyes, prácticas de } \\
\text { aplicación de la ley y otras intervenciones que no tengan en cuenta } \\
\text { la discriminación contra la mujer. }\end{array}$ \\
\hline
\end{tabular}

CEDAW (1979), DEVAW (1993) 
6. OBJETIVO DE DESARROLLO SOSTENIBLE 6: GARANTIZAR LA DISPONIBILIDAD DE AGUA Y SU GESTIÓN SOSTENIBLE Y EL SANEAMIENTO PARA TODOS

La escasez de recursos hídricos, junto con la mala calidad del agua y el saneamiento inadecuado, repercuten en la seguridad alimentaria, los medios de subsistencia y la oportunidad de educación para las familias pobres en todo el mundo. Según un informe de la OMS y UNICEF, 3 de cada 10 personas en el mundo, es decir, 2.100 millones, carecen de acceso a agua potable y de fácil acceso en sus hogares, y 6 de cada 10, es decir, 4.500 millones, carecen de saneamiento gestionado de manera segura. El informe Progress on drinking water, sanitation and hygiene: 2017 update and Sustainable Development Goal baselines (WHO \& UNICEF, 2017) presenta la primera evaluación global de los servicios de agua potable y saneamiento. La conclusión primordial es que todavía hay demasiadas personas sin acceso, especialmente en las zonas rurales.

Las metas 6.a y 6.b establecen, respectivamente, De aquí a 2030, ampliar la cooperación internacional y el apoyo prestado a los países en desarrollo para la creación de capacidad en actividades y programas relativos al agua y el saneamiento, como los de captación de agua, desalinización, uso eficiente de los recursos hídricos, tratamiento de aguas residuales, reciclado y tecnologías de reutilización y Apoyar y fortalecer la participación de las comunidades locales en la mejora de la gestión del agua y el saneamiento. Un ejemplo tecnológico que podría facilitar estos fines son los sistemas de riego portátiles de Futurepump (DNV GL y Sustania, 2019). Se trata de sistemas alimentados por energía solar para uso de los pequeños agricultores. La tubería de succión puede recuperar agua de profundidades de hasta siete metros y medio, lo que la hace ideal para agricultores que dependen de pozos poco profundos, ríos o lagos para regar sus cultivos, y puede bombear hasta un litro por segundo. Las bombas de irrigación solar están actualmente disponibles en nueve países de África y Asia. 
El éxito en la gestión integral de los recursos hídricos es dependiente de la evolución de la dieta y el consumo de alimentos. El aumento previsto en la producción y el consumo de productos de origen animal ejercerá una mayor presión sobre los recursos de agua dulce del planeta. El tamaño y las características de la huella hídrica varían según los tipos de animales y los sistemas de producción. La huella hídrica de la carne de vacuno (15400 m 3 /tonelada como media mundial) es mucho mayor que la de la carne de ovino (10400 m 3 /tonelada), porcino (6000 m 3 /tonelada), caprino ( $5500 \mathrm{~m} 3$ /tonelada) o pollo (4300 m 3 /tonelada). Por tonelada de producto, los productos de origen animal generalmente tienen una mayor huella hídrica que los productos de cultivo. Lo mismo ocurre cuando observamos la huella de agua por caloría. Desde la perspectiva de los recursos de agua dulce, es más eficiente obtener calorías, proteínas y grasas a través de los productos de los cultivos que a través de los productos animales (Gerbens-Leenes, Mekonnen. \& Hoekstra, 2013; Vanham, Hoekstra, \& Bidoglio, G., 2013)

\begin{tabular}{|l|l|}
\hline \multicolumn{1}{|c|}{ Acuerdos y derechos afectados } \\
\hline \multicolumn{1}{|c|}{ Instrumento } & \multicolumn{1}{c|}{ Artículo } \\
\hline $\begin{array}{l}\text { Declaración universal de } \\
\text { los derechos humanos }\end{array}$ & $\begin{array}{l}\text { 22. Toda persona, como miembro de la sociedad, tiene derecho } \\
\text { a la seguridad social, y a obtener, mediante el esfuerzo nacional } \\
\text { y la cooperación internacional, habida cuenta de la organización } \\
\text { y los recursos de cada Estado, la satisfacción de los derechos } \\
\text { económicos, sociales y culturales, indispensables a su dignidad } \\
\text { y al libre desarrollo de su personalidad. }\end{array}$ \\
\hline $\begin{array}{l}\text { Pacto internacional de } \\
\text { derechos económicos, } \\
\text { sociales y culturales }\end{array}$ & $\begin{array}{l}\text { 11.1 Los Estados Partes en el presente Pacto reconocen el } \\
\text { derecho de toda persona a un nivel de vida adecuado para sí y } \\
\text { su familia, incluso alimentación, vestido y vivienda adecuados, } \\
\text { y a una mejora continua de las condiciones de existencia. Los } \\
\text { Estados Partes tomarán medidas apropiadas para asegurar la } \\
\text { efectividad de este derecho, reconociendo a este efecto la } \\
\text { importancia esencial de la cooperación internacional fundada } \\
\text { en el libre consentimiento. }\end{array}$ \\
\hline $\begin{array}{l}\text { Convención de las Naciones } \\
\text { Unidas de Lucha contra la } \\
\text { Desertificación }\end{array}$ & $\begin{array}{l}\text { 3.a Las Partes deben garantizar que las decisiones relativas } \\
\text { a la elaboración y ejecución de programas de lucha contra } \\
\text { la desertificación y mitigación de los efectos de la sequía } \\
\text { se adopten con la participación de la población y de las } \\
\text { comunidades locales y que, a niveles superiores, se cree un } \\
\text { entorno propicio que facilite la adopción de medidas a los } \\
\text { niveles nacional y local. }\end{array}$ \\
\hline
\end{tabular}

UDHR (1948), ICESCR (1966), UNCCD (1994) 

A UNA ENERGÍA ASEQUIBLE, SEGURA, SOSTENIBLE Y MODERNA PARA TODOS

La meta 7.a establece, de aquí a 2030, aumentar la cooperación internacional para facilitar el acceso a la investigación y la tecnología relativas a la energía limpia, inchidas las fuentes renovables, la eficiencia energética y las tecnologías avanzadas y menos contaminantes de combustibles fósiles, y promover la inversión en infraestructura energética y tecnologías limpias. En este sentido, en 2015, Brooklyn Microgrid puso en marcha el proyecto para construir una microrred comunitaria en Brooklyn, Nueva York, donde la energía es generada, almacenada y comercializada localmente por miembros de la comunidad, fomentando así un modelo de energía limpia más resistente y sostenible. La clave se encuentra en una plataforma basada en blockchain llamada Exergy (Papajak, 2017).

Mediante la plataforma Exergy, los prosumidores -que generan energía a través de su propio recurso renovable- pueden realizar transacciones de manera autónoma casi en tiempo real con los consumidores de la plataforma en su mercado local. La plataforma, basada en blockchain, permite, de forma segura, registrar, estandarizar, almacenar y compartir elementos críticos de datos en un ecosistema de recursos energéticos distribuidos. De esta manera, Exergy elimina las barreras no solo hacia la descentralización de la energía sino también hacia la democratización de los datos energéticos.

Un edificio puede generar enormes cantidades de electricidad a través de paneles fotovoltaicos instalados sobre su cubierta. Sin embargo, los edificios vecinos no tienen forma de acceder a este excedente de energía y deben recurrir al suministro de una subestación situada a cientos de kilómetros de distancia. Este sistema es costoso, ineficiente, poco fiable y puede dejar barrios enteros sin energía durante una tormenta u otra emergencia. Para solventar este problema -y tras haber sufrido en Nueva York las consecuencias del huracán Sandy- la empresa emergente LO3 Energy se asoció con el gigante tecnológico Siemens para desarrollar una solución. Surgió así Brooklyn Microgrid, que reinventa el modelo de red de energía tradicional e introduce el concepto de red de energía comunitaria.

Además, existen tecnologías que pueden aumentar considerablemente la proporción de energía renovable en el conjunto de fuentes energéticas, meta 7.2 de este ODS. Bombora Wave Energy ha desarrollado una tecnología para aprovechar la energía constante de las olas. Esta tecnología opera por debajo de la superficie del agua y a una profundidad suficiente para que no afecte al tránsito marino ni se vea afectada por las tormentas. El sistema undimotriz transfiere la energía generada a la costa a través de un cable submarino. En la actualidad, están desarrollando proyectos en Albany, Australia Occidental, Peniche (Portugal), Okrney Islands (Escocia) y, recientemente, Lanzarote. 
El uso intensivo de las tecnologías de la Cuarta Revolución Industrial consume recursos ingentes de energía, lo que puede impactar, si no tienen una procedencia completamente renovable, en el ODS 7 (Energía Asequible y no contaminante) y en el 13 (Acción por el clima). Una muestra del consumo de energía de los sistemas de inteligencia artificial (IA) se encuentra en el estudio de Strubell, Ganesh y McCallum (2019), que se ha centrado en la huella de carbono de las IA entrenadas para comprender cómo funciona el lenguaje humano. Las redes neuronales artificiales son sistemas de cálculo o algoritmos inspirados en el funcionamiento del cerebro humano; imitan lo que ocurre en el cerebro humano, pero dentro de un ordenador. Sus conclusiones son claras: una IA sin "red neuronal" tiene una huella de carbono de unos 650 kilos, mientras que otra con esas características emitiría 285 toneladas (una persona de media al año emite 5 toneladas métricas de $\mathrm{C} 02$, un vuelo Nueva York-San Francisco 0,9 toneladas). La huella de carbono asociada al desarrollo de sistemas de inteligencia artificial crece proporcionalmente a su complejidad. Las redes neuronales producen una mejora en el rendimiento de la IA, a costa de un impacto medioambiental altísimo derivado del gasto que supone poner a funcionar los superordenadores que utilizan para sus cálculos. Este puede ser un ejemplo de las consecuencias ecológicas de la aplicación de las tecnologías de la automatización a todos los procesos de producción.

\begin{tabular}{|l|l|}
\hline \multicolumn{1}{|c|}{ Acuerdos y derechos afectados } \\
\hline \multicolumn{1}{|c|}{ Instrumento } & \multicolumn{1}{c|}{ Artículo } \\
\hline $\begin{array}{l}\text { Convención de las Naciones } \\
\text { Desertificación }\end{array}$ & $\begin{array}{l}19.1 \text { Las Partes reconocen la importancia del fomento de capa- } \\
\text { cidades, esto es, del desarrollo institucional, la formación y la } \\
\text { ampliación de las capacidades locales y nacionales, para los esfuerzos } \\
\text { de lucha contra la desertificación y mitigación de la sequía. Las } \\
\text { Partes promoverán esas capacidades, según corresponda, mediante: } \\
\text { 19.1.f El suministro de capacitación y tecnología adecuadas para } \\
\text { la utilización de fuentes de energía sustitutivas, especialmente } \\
\text { los recursos energéticos renovables, en particular con el fin de } \\
\text { reducir la dependencia de la leña para combustible. }\end{array}$ \\
\hline Acuerdo de París & $\begin{array}{l}\text { 10.2 Las Partes, teniendo en cuenta la importancia de la tecnología } \\
\text { para la puesta en práctica de medidas de mitigación y adaptación } \\
\text { en virtud del presente Acuerdo y tomando en consideración } \\
\text { los esfuerzos de difusión y despliegue de tecnología que ya se } \\
\text { están realizando, deberán fortalecer su acción cooperativa en el } \\
\text { desarrollo y la transferencia de tecnología. } \\
\text { 10.5 Para dar una respuesta mundial eficaz y a largo plazo al } \\
\text { cambio climático y promover el crecimiento económico y el } \\
\text { desarrollo sostenible es indispensable posibilitar, alentar y acelerar } \\
\text { la innovación. Este esfuerzo será respaldado como corresponda, } \\
\text { entre otros por el Mecanismo Tecnológico y, con medios finan- } \\
\text { cieros, por el Mecanismo Financiero de la Convención, a fin de } \\
\text { impulsar los enfoques colaborativos en la labor de investigación } \\
\text { y desarrollo y de facilitar el acceso de las Partes que son países } \\
\text { en desarrollo a la tecnología, en particular en las primeras etapas } \\
\text { del ciclo tecnológico. }\end{array}$ \\
\hline
\end{tabular}

UNCCD (1994); UNFCCC (2015) 


\section{OBJETIVO DE DESARROLLO SOSTENIBLE 8: PROMOVER EL CRECIMIENTO ECONÓMICO SOSTENIDO, INCLUSIVO Y SOSTENIBLE, EL EMPLEO PLENO Y PRODUCTIVO Y EL TRABAJO DECENTE PARA TODOS}

La cuarta revolución industrial tendrá un impacto determinante en la economía mundial. De hecho, todas las grandes macrovariables -PIB, inversión, consumo, empleo, comercio, inflación- resultarán afectadas. El impacto que la cuarta revolución industrial tendrá en el crecimiento económico es un tema que divide a los economistas. Por un lado, los tecnopesimistas argumentan que ya se han hecho las aportaciones críticas de la revolución digital y que su impacto sobre la productividad ya casi ha finalizado. En el campo opuesto, los tecnooptimistas afirman que la tecnología y la innovación se encuentran en un punto de inflexión y que pronto desatarán un aumento de la productividad y un mayor crecimiento económico (Schwab, 2016). Este es un elemento clave para el ODS 8, pues la meta 8.2 plantea Lograr niveles más elevados de productividad económica mediante la diversificación, la modernización tecnológica y la innovación, entre otras cosas centrándose en los sectores con gran valor añadido y un uso intensivo de la mano de obra.

Las razones por las cuales la nueva revolución tecnológica provocará más revuelo que las anteriores revoluciones industriales son la velocidad (todo está sucediendo a un ritmo mucho más rápido que nunca), la amplitud y profundidad (muchos cambios radicales se producen simultáneamente), y la completa transformación de sistemas enteros. A la luz de estos factores impulsores, hay una certeza: las nuevas tecnologías cambiarán profundamente la naturaleza del trabajo en todas las industrias y ocupaciones. La incertidumbre fundamental tiene que ver con la medida en que la automatización sustituya a la mano de obra. ¿Cuánto tiempo tardará y hasta dónde llegará?

A pesar del impacto positivo potencial de la tecnología en el crecimiento económico, es esencial atender a su posible impacto negativo, al menos a corto plazo, en el mercado laboral (Andreu \& Fernández, 2019, 17 de septiembre). El impacto de la automatización y la robótica en el trabajo afecta al ODS 8 (trabajo decente y crecimiento económico), particularmente a la meta 8.5 que establece lo siguiente: De aquí a 2030, lograr el empleo pleno y productivo y el trabajo decente para todas las mujeres y los hombres, incluidos los jóvenes y las personas con discapacidad, así como la igualdad de remuneración por trabajo de igual valor. En 2014, las tres compañías más grandes de Detroit y las tres compañías más grandes de Silicon Valley generaron aproximadamente los mismos ingresos; pero en Silicon Valley había 10 veces menos empleados. Al usar inteligencia artificial, una empresa puede reducir drásticamente la dependencia de la fuerza de trabajo humana, y esto significa que los ingresos irán a menos personas. Los accionistas de las nuevas plataformas tecnológicas, impulsadas por inteligencia artificial, están empezando a acumular una riqueza que claramente incrementa las desigualdades (en contra de lo que persigue el ODS 10). 


\begin{tabular}{|l|l|}
\hline \multicolumn{2}{|c|}{ Acuerdos y derechos afectados } \\
\hline \multicolumn{1}{|c|}{ Instrumento } & \multicolumn{1}{c|}{ Artículo } \\
\hline $\begin{array}{l}\text { Declaración universal de los } \\
\text { derechos humanos }\end{array}$ & $\begin{array}{l}\text { 23.1 Toda persona tiene derecho al trabajo, a la libre elección } \\
\text { de su trabajo, a condiciones equitativas y satisfactorias de } \\
\text { trabajo y a la protección contra el desempleo. } \\
\text { 23.3 Toda persona que trabaja tiene derecho a una remune- } \\
\text { ración equitativa y satisfactoria, que le asegure, asi como a } \\
\text { su familia, una existencia conforme a la dignidad humana } \\
\text { y que sera completada, en caso necesario, por cualesquiera } \\
\text { otros medios de protección social. }\end{array}$ \\
\hline $\begin{array}{l}\text { Pacto internacional de } \\
\text { derechos económicos, } \\
\text { sociales y culturales }\end{array}$ & $\begin{array}{l}\text { 6.2 Entre las medidas que habrá de adoptar cada uno de } \\
\text { los Estados Partes en el presente Pacto para lograr la plena } \\
\text { efectividad de este derecho deberá figurar la orientación y } \\
\text { formación técnico-profesional, la preparación de programas, } \\
\text { normas y técnicas encaminadas a conseguir un desarrollo } \\
\text { económico, social y cultural constante y la ocupación } \\
\text { plena y productiva, en condiciones que garanticen las } \\
\text { libertades políticas y económicas fundamentales de la } \\
\text { persona humana. }\end{array}$ \\
\hline
\end{tabular}

UDHR (1948), ICESCR (1966)

\section{OBJETIVO DE DESARROLLO SOSTENIBLE 9: CONSTRUIR INFRAES- TRUCTURAS RESILIENTES, PROMOVER LA INDUSTRIALIZACIÓN INCLUSIVA Y SOSTENIBLE Y FOMENTAR LA INNOVACIÓN}

Respecto a las infraestructuras, la descarbonización del transporte de mercancías por carretera mediante transporte convencional es difícil, por lo que se han desarrollado nuevas alternativas. La electrificación del transporte de mercancías por carretera es una de las soluciones viables. El cambio hacia los vehículos eléctricos de carga parece ser técnicamente y financieramente factible, ya que no se necesitan baterías a bordo (que lo dificultarían por el coste el y tamaño). Esta alternativa lograría una reducción del 73\% de emisiones de CO2 en promedio en comparación con los vehículos convencionales de transporte de mercancías. La reducción podría alcanzar el 91\% para 2040, factible siempre que se cumplan las previsiones actuales de descarbonización de la red eléctrica (Nicolaides, Cebon y Miles, 2017). 
Las primeras pruebas y testados del sistema eHighway comenzaron en 2010, en una carretera privada a las afueras de Berlín. Desde entonces, tres proyectos de investigación y desarrollo financiados parcialmente por el Ministerio Federal de Medio Ambiente de Alemania se han ejecutado con éxito. En 2016 se construyó la primera eHighway en una autopista pública -un proyecto liderado por Siemens con el fabricante de camiones Scania-. Durante dos años, un sistema de catenaria de Siemens para camiones fue probado en un tramo de dos kilómetros de la autopista al norte de Estocolmo. Desvincular a los camiones de su dependencia con los combustibles fósiles es una necesidad, y la eHighway es el primer paso. En 2017, aparece una segunda autopista eléctrica entre Los Ángeles y Long Beach (California), en este caso en colaboración con Volvo (Siemens, 2017).

Dentro del ODS 9, la meta 9.C plantea aumentar significativamente el acceso a la tecnología de la información y las comunicaciones y esforzarse por proporcionar acceso universal y asequible a Internet en los países menos adelantados de aqui a 2020. Desde 2006, Bluetown (DNV GL y Sustania, 2019) ha estado desarrollando y distribuyendo estaciones de internet asequibles para poblaciones desconectadas en áreas semiurbanas, rurales y remotas. Durante los próximos cinco años se espera utilizar su solución para garantizar el acceso seguro a más de 100 millones de personas en sus cuatro regiones objetivo: África, Oriente Medio, India y Sudamérica. La solución de Bluetown es una estación base alimentada por energía solar que proporciona una conexión wifi dentro de un radio de acción de un kilómetro. Estas estaciones de internet se conectan a la infraestructura de internet existente.

Gracias a los satélites, las comunidades de estas regiones pueden tener un acceso seguro a internet en las zonas más remotas. Una sola conexión a internet puede utilizarse para dar servicio a varias aldeas, ya que las estaciones base pueden conectarse entre sí. Al ser totalmente alimentadas por energía solar, no tienen que estar conectadas a una red de energía centralizada, lo que las hace especialmente eficaces en zonas remotas. Además, están equipados con un sistema de baterías para almacenar el exceso de energía, lo que significa que también se pueden utilizar para cargar dispositivos.

Algunos de los enormes beneficios de esta tecnología se encuentran en la salud y la educación, ya que permite a las personas acceder a fuentes de información actualizadas desarrolladas por los gobiernos, las ONG y las empresas. Por ejemplo, las enfermeras tendrían acceso a guías clínicas actualizadas para ayudar a mejorar la calidad de la atención médica. 
La meta 9.4 plantea, de aquí a 2030, modernizar la infraestructura y reconvertir las industrias para que sean sostenibles, utilizando los recursos con mayor eficacia y promoviendo la adopción de tecnologías y procesos industriales limpios y ambientalmente racionales, y logrando que todos los países tomen medidas de acuerdo con sus capacidades respectivas. Las tierras raras son un conjunto de 17 minerales que, por sus propiedades naturales, tienen un papel clave en la fabricación de numerosos dispositivos electrónicos. Para la fabricación de paneles, baterías recargables o circuitos complejos se emplean determinados tipos de minerales como el imán de neodimio, el indio, el praseodimio o el disprosio. La demanda de todos ellos se multiplicará durante los próximos años, siguiendo el interés de muchos gobiernos por las energías renovables. Antes de 2050, podríamos necesitar doce veces más indio o siete veces más neodimio que hoy. En 2017, China produjo más del $80 \%$ de la oferta mundial. En los últimos años, China ha perdido preeminencia en el mercado por el incremento decidido de la producción y las exportaciones australianas. Se estima que China sólo representa un 50\% de las reservas mundiales de tierras raras. Lidera la lista, pero países como Brasil, Rusia, Vietnam o India le siguen de cerca en cuanto a yacimientos conocidos. Reservas que no han sido explotadas por el enorme impacto ambiental que tiene su extracción. Explotar estas reservas es casi sinónimo a catástrofe medioambiental (Jiménez, 2019).

\begin{tabular}{|c|c|}
\hline \multicolumn{2}{|r|}{ Acuerdos y derechos afectados } \\
\hline Instrumento & Artículo \\
\hline $\begin{array}{l}\text { Convención Marco de las } \\
\text { Naciones Unidas sobre el } \\
\text { Cambio Climático }\end{array}$ & $\begin{array}{l}\text { 4.1Todas las Partes, teniendo en cuenta sus responsabilidades } \\
\text { comunes pero diferenciadas y el carácter específico de sus } \\
\text { prioridades nacionales y regionales de desarrollo, de sus objetivos } \\
\text { y de sus circunstancias, deberán: } \\
\text { 4.1.c Promover y apoyar con su cooperación el desarrollo, la } \\
\text { aplicación y la difusión, incluida la transferencia, de tecnologías, } \\
\text { prácticas y procesos que controlen, reduzcan o prevengan las } \\
\text { emisiones antropógenas de gases de efecto invernadero no } \\
\text { controlados por el Protocolo de Montreal en todos los sectores } \\
\text { pertinentes, entre ellos la energía, el transporte, la industria, la } \\
\text { agricultura, la silvicultura y la gestión de desechos } \\
\text { 4.5 Las Partes que son países desarrollados y las demás Partes } \\
\text { desarrolladas que figuran en el anexo II tomarán todas las medidas } \\
\text { posibles para promover, facilitar y financiar, según proceda, la } \\
\text { transferencia de tecnologías y conocimientos prácticos ambien- } \\
\text { talmente sanos, o el acceso a ellos, a otras Partes, especialmente } \\
\text { las Partes que son países en desarrollo, a fin de que puedan } \\
\text { aplicar las disposiciones de la Convención. En este proceso, las } \\
\text { Partes que son países desarrollados apoyarán el desarrollo y el } \\
\text { mejoramiento de las capacidades y tecnologías endógenas de las } \\
\text { Partes que son países en desarrollo. Otras Partes y organizaciones } \\
\text { que estén en condiciones de hacerlo podrán también contribuir } \\
\text { a facilitar la transferencia de dichas tecnologías. }\end{array}$ \\
\hline
\end{tabular}

UNFCCC (1992) 


\section{OBJETIVO DE DESARROLLO SOSTENIBLE 10: REDUCIR LA DESIGUALDAD EN Y ENTRE LOS PAÍSES}

Las nuevas tecnologías de la automatización tienen un efecto potencial en la actividad industrial que se está convirtiendo en un foco importante de preocupación; los gobiernos de todo el mundo, en especial los asiáticos y norteamericanos, están desarrollando sus propias estrategias en inteligencia artificial.

La Comisión Europea, desde el European Political Strategy Centre (EPSC), está empezando a desarrollar su propia estrategia de inteligencia artificial. Perder la carrera mundial por el liderazgo en la inteligencia artificial tendría un efecto perjudicial en la manufactura europea, y por lo tanto en trabajo, crecimiento e innovación. Según este centro, se debería reconducir la dirección de la tecnología en función de estándares globales y mejores prácticas, asegurándose que todas las tecnologías basadas en inteligencia artificial aumenten el valor de la sociedad, y que este valor se comparta lo más ampliamente posible. Las inquietudes éticas tienen un gran peso y suponen un mandato moral europeo (EPSC, 2018).

Dado que las tecnologías de automatización desempeñan un papel cada vez más importante en la vida cotidiana, su efecto potencial en el lugar de trabajo -qué puestos serán remplazados por máquinas- ha abierto líneas de investigación y preocupación pública (Chui, Manyika \& Miremadi, 2016; Condliffe, 2017). Los optimistas afirman que las máquinas inteligentes liberarán a las personas de las tareas más tediosas y colaborarán con nosotros facilitando el desarrollo del trabajo creativo.

Labores administrativas y de oficina, manufacturas y cadenas de montaje son empleos en situación de riesgo. Los pesimistas creen que se perderán gran cantidad de puestos de trabajo, los más propensos a la automatización. Al usar inteligencia artificial, una empresa puede reducir drásticamente la dependencia de la fuerza de trabajo humana, y esto significa que los ingresos irán a menos personas. Los accionistas de las nuevas plataformas tecnológicas, impulsadas por inteligencia artificial, están empezando a acumular una riqueza que claramente incrementa las desigualdades (Andreu \& Fernández, 2019, 17 de septiembre). Sin una adecuada distribución de los ingresos de las grandes empresas digitales será difícil lograr las metas de este objetivo, como la meta 10.1 Lograr progresivamente y mantener el crecimiento de los ingresos del 40\% más pobre de la población, 10.2 Potenciar y promover la inclusión social, económica y política de todas las personas y 10.3 Garantizar la igualdad de oportunidades y reducir la desigualdad de resultados 


\begin{tabular}{|l|l|}
\hline \multicolumn{1}{|c|}{ Acuerdos y derechos afectados } \\
\hline \multicolumn{1}{|c|}{ Instrumento } & \multicolumn{1}{c|}{ Artículo } \\
\hline $\begin{array}{l}\text { Declaración universal de los } \\
\text { derechos humanos }\end{array}$ & $\begin{array}{l}\text { 22.Toda persona, como miembro de la sociedad, tiene derecho a } \\
\text { la seguridad social, y a obtener, mediante el esfuerzo nacional y } \\
\text { la cooperación internacional, habida cuenta de la organización } \\
\text { y los recursos de cada Estado, la satisfacción de los derechos } \\
\text { económicos, sociales y culturales, indispensables a su dignidad } \\
\text { y al libre desarrollo de su personalidad. } \\
\text { 25.1 Toda persona tiene derecho a un nivel de vida adecuado } \\
\text { que le asegure, así como a su familia, la salud y el bienestar, y } \\
\text { en especial la alimentación, el vestido, la vivienda, la asistencia } \\
\text { médica y los servicios sociales necesarios; tiene asimismo derecho } \\
\text { a los seguros en caso de desempleo, enfermedad, invalidez, viudez, } \\
\text { vejez y otros casos de pérdida de sus medios de subsistencia por } \\
\text { circunstancias independientes de su voluntad. }\end{array}$ \\
\hline $\begin{array}{l}\text { Pacto internacional de } \\
\text { derechos económicos, } \\
\text { sociales y culturales }\end{array}$ & $\begin{array}{l}\text { 11.1 Los Estados Partes en el presente Pacto reconocen el } \\
\text { derecho de toda persona a un nivel de vida adecuado para sí y } \\
\text { su familia, incluso alimentación, vestido y vivienda adecuados, } \\
\text { y a una mejora continua de las condiciones de existencia. } \\
\text { Los Estados Partes tomarán medidas apropiadas para asegurar } \\
\text { la efectividad de este derecho, reconociendo a este efecto la } \\
\text { importancia esencial de la cooperación internacional fundada } \\
\text { en el libre consentimiento. }\end{array}$ \\
\hline
\end{tabular}

UDHR (1948), ICESCR (1966)

\section{OBJETIVO DE DESARROLLO SOSTENIBLE 11: LOGRAR QUE LAS CIUDADES Y LOS ASENTAMIENTOS HUMANOS SEAN INCLUSIVOS, SEGUROS, RESILIENTES Y SOSTENIBLES}

La meta 11.6 plantea reducir el impacto ambiental negativo per capita de las ciudades, incluso prestando especial atención a la calidad del aire y la gestión de los desechos municipales y de otro tipo. Everimpact (DNV GL \& Sustania, 2019), proporciona la tecnología para medir las emisiones de gases de efecto invernadero y la calidad del aire en ciudades y regiones. Su plataforma proporciona datos en tiempo real, permitiendo a los usuarios medir la eficacia de las políticas y participar en el comercio de emisiones. Utiliza una combinación de datos procedentes de satélites y sensores terrestres para medir las emisiones de gases de efecto invernadero en ciudades y regiones en tiempo real. Asociarse con organismos como la Agencia Espacial Europea (ESA) y el Grupo de Observación de la Tierra (GEO), le ha permitido acceder a datos de alta calidad. La finalidad es instalar sensores en ciudades 
para medir y comparar las emisiones y la calidad del aire en diferentes áreas de la ciudad a lo largo del día.

Con las herramientas de visualización de datos de Everimpact, las ciudades pueden estar mejor equipadas para medir la calidad del aire ciudades. En particular, permite a las ciudades identificar los puntos críticos en los que los ciudadanos pueden estar expuestos a altos niveles de contaminación atmosférica y realizar cambios para reducir los riesgos para la salud.

El 70\% de las emisiones que están impulsando el cambio climático en nuestro planeta provienen de las ciudades. Esto plantea un desafío claro y urgente: las ciudades deben volver a pensarse. El informe El peso de las ciudades: los recursos que exige la urbanización del futuro, considera que las ciudades deben ser bajas en carbono, eficientes en recursos y socialmente justas (IRP, 2018). El aumento de la población mundial, estimado en 2500 millones de personas para 2050, significa que las nuevas ciudades, asi como las existentes, deberán acomodar a gran parte de dicha población. Dependiendo de las decisiones que tomemos, los problemas existentes en las ciudades tales como la contaminación, la congestión, la falta de infraestructura o servicios públicos y la inequidad social se podrían exacerbar. La tecnología ha permitido un mundo complejo lleno de facilidades, pero al mismo tiempo se necesita una reformulación de la infraestructura tecnológica de las ciudades para lograr espacios sostenibles. De lo contrario será imposible lograr la meta 11.3, aumentar la urbanización inclusiva y sostenible o la meta 11.6, reducir el impacto ambiental negativo per capita de las ciudades.

\begin{tabular}{|l|l|}
\hline \multicolumn{1}{|c|}{ Instrumento } & \multicolumn{1}{c|}{ Acuerdos y derechos afectados } \\
\hline $\begin{array}{l}\text { Pacto internacional de } \\
\text { derechos económicos, } \\
\text { sociales y culturales }\end{array}$ & $\begin{array}{l}\text { 12.1 Los Estados Partes en el presente Pacto reconocen el } \\
\text { derecho de toda persona al disfrute del más alto nivel posible } \\
\text { de salud física y mental. } \\
\text { 12.2.b } \\
\text { El mejoramiento en todos sus aspectos de la higiene del trabajo } \\
\text { y del medio ambiente. }\end{array}$ \\
\hline $\begin{array}{l}\text { Convención Marco de las } \\
\text { Cambio Climático }\end{array}$ & $\begin{array}{l}\text { 4.1.c Promover y apoyar con su cooperación el desarrollo, la } \\
\text { aplicación y la difusión, incluida la transferencia, de tecnologías, } \\
\text { prácticas y procesos que controlen, reduzcan o prevengan las } \\
\text { emisiones antropógenas de gases de efecto invernadero no } \\
\text { controlados por el Protocolo de Montreal en todos los sectores } \\
\text { pertinentes, entre ellos la energía, el transporte, la industria, la } \\
\text { agricultura, la silvicultura y la gestión de desechos. }\end{array}$ \\
\hline Acuerdo de París & $\begin{array}{l}\text { 2.1.b Aumentar la capacidad de adaptación a los efectos adversos } \\
\text { del cambio climático y promover la resiliencia al clima y un } \\
\text { desarrollo con bajas emisiones de gases de efecto invernadero, } \\
\text { de un modo que no comprometa la producción de alimentos }\end{array}$ \\
\hline
\end{tabular}

ICESCR (1966), UNFCCC (1992), UNFCCC (2015) 


\section{OBJETIVO DE DESARROLLO SOSTENIBLE 12: GARANTIZAR MODALIDADES DE CONSUMO Y PRODUCCIÓN SOSTENIBLES}

Con sede en Finlandia, Loudspring (DNV GL y Sustania, 2019) es un grupo industrial centrado en el ahorro de recursos naturales a través de negocios nórdicos respetuosos con el medio ambiente. Se centran en cinco industrias globales: la alimentaria y la de la moda, de energía, manufactura e inmobiliaria, y cada año califican el impacto de sus inversiones en las emisiones de carbono y en el uso del agua. En 2017, la empresa estimó que había ahorrado 158.000 toneladas de dióxido de carbono y 13,7 millones de metros cúbicos de agua dulce. Las empresas de Loudspring tienen un impacto positivo directo y medible en el medio ambiente. Ahorran cantidades significativas de energía en la industria manufacturera y en el sector inmobiliario, dos de los principales sectores consumidores de energía a nivel mundial. Pueden impedir que los microplásticos entren en nuestros océanos, aumentar la eficiencia en la producción de energía y facilitar la transición a energía renovable y baja en carbono. Sus empresas lideran la transición a una economía circular, con negocios que operan en el mercado digital de segunda mano o el de excedentes de comida de restaurantes. Todos estos aspectos inciden positivamente en casi todas las metas de este ODS, en especial las metas 12.3 reducir a la mitad el desperdicio de alimentos", 12.4 "lograr la gestión ecológicamente racional de los productos químicos y de todos los desechos a lo largo de su ciclo de vida" y 12.5 "reducir considerablemente la generación de desechos mediante actividades de prevención, reducción, reciclado y reutilización.

El Panel Internacional de Recursos de Naciones Unidas ha presentado evaluaciones científicas sobre las tendencias, los modelos y las consecuencias de la extracción, la utilización y la eliminación de los recursos naturales en nuestras sociedades y economías. En las últimas cinco décadas nuestra población mundial se ha duplicado, la extracción de materiales se ha triplicado y el producto interno bruto se ha cuadruplicado. La extracción y el procesamiento de los recursos naturales se ha acelerado en las dos últimas décadas y es responsable de más del 90 por ciento de nuestra pérdida de biodiversidad, del estrés hídrico y de aproximadamente la mitad de los impactos relacionados con el cambio climático. En los últimos 50 años no hemos experimentado una sola vez un período prolongado de estabilización ni una disminución en la demanda mundial de materiales. Para ONU Medio Ambiente, es necesario un consumo más responsable y explorar formas de alimentación que logren un equilibrio ecológico Como afirma el Global Resources Outlook de 2019, elaborado por el Panel Internacional de Recursos, sería positivo adoptar medidas para la reducción simultánea de varios impactos negativos, que pasarían por el cambio a las dietas con menos carne, evitando productos animales procedentes de los sistemas de ganadería intensiva (Oberle et al., 2019). 


\section{Acuerdos y derechos afectados}

\begin{tabular}{|c|c|}
\hline Instrumento & Artículo \\
\hline $\begin{array}{l}\text { Pacto internacional de } \\
\text { derechos económicos, } \\
\text { sociales y culturales }\end{array}$ & $\begin{array}{l}\text { 11.1 Los Estados Partes en el presente Pacto reconocen el } \\
\text { derecho de toda persona a un nivel de vida adecuado para } \\
\text { sí y su familia, incluso alimentación, vestido y vivienda } \\
\text { adecuados, y a una mejora continua de las condiciones de } \\
\text { existencia. Los Estados Partes tomarán medidas apropiadas } \\
\text { para asegurar la efectividad de este derecho, reconociendo } \\
\text { a este efecto la importancia esencial de la cooperación } \\
\text { internacional fundada en el libre consentimiento. } \\
\text { 11.2.a Mejorar los métodos de producción, conservación } \\
\text { y distribución de alimentos mediante la plena utilización } \\
\text { de los conocimientos técnicos y científicos, la divulgación } \\
\text { de principios sobre nutrición y el perfeccionamiento o la } \\
\text { reforma de los regímenes agrarios de modo que se logren } \\
\text { la explotación y la utilización más eficaces de las riquezas } \\
\text { naturales. } \\
\text { 11.2.b Asegurar una distribución equitativa de los alimentos } \\
\text { mundiales en relación con las necesidades, teniendo en } \\
\text { cuenta los problemas que se plantean tanto a los países } \\
\text { que importan productos alimenticios como a los que los } \\
\text { exportan. }\end{array}$ \\
\hline $\begin{array}{l}\text { La Convención de las } \\
\text { Naciones Unidas sobre el } \\
\text { Derecho del Mar }\end{array}$ & $\begin{array}{l}\text { 207.1 Los Estados dictarán leyes y reglamentos para pre- } \\
\text { venir, reducir y controlar la contaminación del medio } \\
\text { marino procedente de fuentes terrestres, incluidos los } \\
\text { ríos, estuarios, tuberías y estructuras de desagüe, teniendo } \\
\text { en cuenta las reglas y estándares, así como las prácticas y } \\
\text { procedimientos recomendados, que se hayan convenido } \\
\text { internacionalmente. } \\
207.2 \text { Los Estados tomarán otras medidas que puedan ser } \\
\text { necesarias para prevenir, reducir y controlar esa conta- } \\
\text { minación. }\end{array}$ \\
\hline $\begin{array}{l}\text { La Convención de Basilea } \\
\text { sobre el control de los } \\
\text { movimientos transfronterizos } \\
\text { de los desechos peligrosos y } \\
\text { su eliminación }\end{array}$ & $\begin{array}{l}\text { 4.2 Cada Parte tomará las medidas apropiadas para: } \\
\text { 4.2.a Reducir al mínimo la generación de desechos peligrosos } \\
\text { y otros desechos en ella, teniendo en cuenta los aspectos } \\
\text { sociales, tecnológicos y económicos. }\end{array}$ \\
\hline
\end{tabular}

ICESCR (1966), UNCLOS (1982), Basel Convention (1989) 


\section{OBJETIVO DE DESARROLLO SOSTENIBLE 13: ADOPTAR MEDIDAS URGENTES PARA COMBATIR EL CAMBIO CLIMÁTICO Y SUS EFECTOS}

Uno de los elementos esenciales de la lucha contra el cambio climático es la transición hacia un modelo de producción y uso de energía mucho menos impactante para el medio ambiente y las personas. Wilfred Malembaum (1978) sugirió que en la mayoría de las regiones económicas del planeta la intensidad de uso de los principales recursos minerales (medida a través de la demanda de materiales por unidad de PIB) había declinado considerablemente entre 1951 y 1975, presagiando una continuación de la misma tendencia, entre 1985 y 2000. Esta tendencia decreciente estaba fundamentada en tres factores: los cambios en el consumo final de bienes y servicios, el progreso tecnológico que aumenta la eficiencia en el uso de los recursos reduciendo también la generación de residuos y, por último, la sustitución de materias primas tradicionales por otras nuevas más eficientes, espoleadas por los movimientos de precios y el desarrollo tecnológico. Esta circunstancia, unida al hecho de que, al calor de la crisis energética, algunos países mostraran una reducción de la utilización de energía por unidad de PIB, parecía presagiar una progresiva independencia del crecimiento económico respecto del consumo de energía y recursos naturales, apuntando así la posibilidad de una singular desmaterialización de la economía.

En esta línea, los estudios de Jänicke, Mönch, Ranneberg y Simonis (1989) concluían que, entre 1970 y 1985, se había producido, simultáneamente, un aumento del PIB y una reducción en la utilización de aquellos flujos de recursos naturales en varios países como Francia, Suecia, Alemania o Gran Bretaña, como consecuencia de un cambio estructural de sus economías. En los 90, las nuevas tecnologías de la información serían las encargadas de reflotar las tesis desmateralizadoras, siendo la solución al deterioro ecológico. La nueva economía digital permitiría un tipo diferente de crecimiento económico, menos consumidor de materiales y energía. La desmaterialización de la economía, debido al trabajo en red, internet y la eficiencia en el transporte, entre otros muchos factores, dará lugar a un nuevo concepto, la e-materialización (Romm, Rosenfeld y Herrmann, 1999).

Comprender las implicaciones en materia de carbono de las tecnologías de la información y la comunicación (TIC) es fundamental para hacer frente a los desafíos del cambio climático en la era digital. Según el informe Smart 2020, realizado por GeSI y The Climate Group, las nuevas aplicaciones de las TIC permitirán multiplicar por cinco la reducción de emisiones en los sectores de la edificación, el transporte y la logística hasta alcanzar el 15\% de las emisiones 
actuales, lo que supone un porcentaje muy importante en la lucha contra el cambio climático. La construcción de edificios inteligentes (smart buildings) -que reducirán un 15\% las emisiones-, la gestión inteligente de redes energéticas (smart grids) -que supondrá reducir 2,03 GtCO2e de emisiones globales y un ahorro de 79.000 millones de euros- o el incremento de la eficiencia en actividades de almacenamiento, transporte y logística de mercancías -que supondría reducir en un 16\% las emisiones del sector transporte y en más de la cuarta parte de las asociadas a los enclaves logísticos- son algunos de los efectos positivos que pueden generar la implementación de las TIC en materia de emisiones (GeSI, 2008).

A lo largo de este trabajo hemos mencionado cómo las tecnologías de la cuarta revolución industrial pueden suponer un incremento sustancial de las emisiones de carbono debido al ingente consumo energético de algunos de los nuevos artefactos tecnológicos. Más allá del aspecto puramente tecnológico, la Justicia Climática es un concepto que sirve para enmarcar el caos climático como un problema ético y político y no solo como un fenómeno puramente medioambiental o físico. La conexión ética y política se logra relacionando los efectos del cambio climático con conceptos de justicia, particularmente la justicia medioambiental y la justicia social, con problemáticas tales como la igualdad, los Derechos Humanos o la responsabilidad histórica por el caos climático. El cambio climático moldeará irremediablemente la forma en la que conocemos las democracias, pero, sobre todo, se hace hincapié en cómo una democracia más justa puede moldear los efectos sobre las sociedades que tendrá, y tiene, el caos climático (Franco-Barrera, 2019b)

\begin{tabular}{|l|l|}
\hline \multicolumn{1}{|c|}{ Acuerdos y derechos afectados } \\
\hline $\begin{array}{l}\text { Instrumento } \\
\text { Declaración universal de } \\
\text { los derechos humanos }\end{array}$ & $\begin{array}{l}\text { 3. Todo individuo tiene derecho a la vida, a la libertad y } \\
\text { a la seguridad de su persona. }\end{array}$ \\
\hline $\begin{array}{l}\text { Pacto internacional de } \\
\text { derechos civiles y políticos }\end{array}$ & $\begin{array}{l}\text { 6.1 El derecho a la vida es inherente a la persona humana. } \\
\text { Este derecho estará protegido por la ley. Nadie podrá ser } \\
\text { privado de la vida arbitrariamente. }\end{array}$ \\
\hline $\begin{array}{l}\text { Convención Marco de las } \\
\text { Naciones Unidas sobre el } \\
\text { Cambio Climático }\end{array}$ & En su totalidad \\
\hline Acuerdo de París & En su totalidad \\
\hline
\end{tabular}

UDHR (1948), ICCPR (1966), UNFCCC (1992), UNFCCC (2015) 


\section{OBJETIVO DE DESARROLLO SOSTENIBLE 14: CONSERVAR Y UTILIZAR EN FORMA SOSTENIBLE LOS OCÉANOS, LOS MARES Y LOS RECURSOS MARINOS PARA EL DESARROLLO SOSTENIBLE}

Los estudios sugieren que trillones de partículas microplásticas flotan en la superficie de los océanos del mundo y que la cantidad total de desechos plásticos que entran en el océano aumentará en un orden de magnitud para 2025 (Rochman, 2016). Para solucionar este problema que afecta a los ecosistemas marinos, Boyan Slat creó The Ocean Cleanup, una compañía que desarrolla tecnologías avanzadas para librar a los océanos de los residuos plásticos gracias a unos sistemas pasivos en forma de barreras o diques de contención que, en teoría, podrían eliminar aproximadamente la mitad de la basura del Pacífico en 10 años.

Sherman y van Sebille (2016) estudiaron este proyecto y, basándose en sus resultados, afirman que la limpieza de los océanos reducirá de manera más efectiva la cantidad de microplásticos y la interacción entre los microplásticos y la vida silvestre cuando los esfuerzos se concentran más cerca de la orilla, en lugar de en el medio del océano. En términos generales, sugieren que será más rentable y ecológicamente beneficioso limpiar el plástico cerca de las costas antes de que se hunda y/o sea ingerido por la fauna. Específicamente, sugieren que los lugares óptimos de limpieza se encuentran principalmente frente a la costa de China y en el Archipiélago de Indonesia, donde las fuentes son relativamente grandes (Jambeck et al., 2015) y los modelos de circulación sugieren que los desechos se dispersarán con relativa rapidez.

El Informe Especial sobre el Océano y la Criosfera del Panel Intergubernamental sobre el Cambio Climático (IPCC, 2019) alerta sobre el aumento del nivel del mar, el incremento de su temperatura y acidez, así como de la disminución de los niveles de oxígeno en el agua, que ocasiona la reducción de poblaciones de peces en muchas regiones y la muerte de arrecifes de coral. Estos efectos limitan la consecución de la meta 14.2 Gestionar y proteger sosteniblemente los ecosistemas marinos y costeros para evitar efectos adversos importantes, incluso fortaleciendo su resiliencia, y adoptar medidas para restaurarlos a fin de restablecer la salud y la productividad de los océanos y 14.3 Minimizar y abordar los efectos de la acidificación de los océanos, incluso mediante una mayor cooperación científica a todos los niveles. Según el informe, si bien el nivel del mar ha aumentado en todo el mundo alrededor de 15 centímetros durante el siglo XX, actualmente aumenta más del doble de rápido (3.6 milímetros por año) y se acelera. El nivel del mar seguirá aumentando durante siglos y podría alcanzar alrededor de 30 a 60 centímetros para 2100, incluso si las emisiones de gases de efecto invernadero se reducen drásticamente y el calentamiento global se limita a muy por debajo de 2 grados centígrados. Una vez más se demuestra el carácter interconectado y holístico de los ODS, y la necesidad de acelerar las transformaciones tecnológicas para corresponder con los criterios científicos deseables en términos de resiliencia y sostenibilidad. 
Acuerdos y derechos afectados

\begin{tabular}{|c|c|}
\hline Instrumento & Artículo \\
\hline La Convención de las & 61.2 El Estado ribereño, teniendo en cuenta los datos científicos \\
\hline
\end{tabular}

Naciones Unidas sobre más fidedignos de que disponga, asegurará, mediante medidas el Derecho del Mar adecuadas de conservación y administración, que la preservación de los recursos vivos de su zona económica exclusiva no se vea amenazada por un exceso de explotación. El Estado ribereño y las organizaciones internacionales competentes, sean subregionales, regionales o mundiales, cooperarán, según proceda, con este fin. 200. Los Estados cooperarán, directamente o por conducto de las organizaciones internacionales competentes, para promover estudios, realizar programas de investigación científica y fomentar el intercambio de la información y los datos obtenidos acerca de la contaminación del medio marino. Procurarán participar activamente en los programas regionales y mundiales encaminados a obtener los conocimientos necesarios para evaluar la naturaleza y el alcance de la contaminación, la exposición a ella, su trayectoria y sus riesgos y remedios.

Convenio sobre la Diversidad Biológica

En su totalidad para la meta 14.2 , siendo significativos para la meta 14.3:

12.a Establecerán y mantendrán programas de educación y capacitación científica y técnica en medidas de identificación, conservación y utilización sostenible de la diversidad biológica y sus componentes y prestarán apoyo para tal fin centrado en las necesidades específicas de los países en desarrollo;

12.b Promoverán y fomentarán la investigación que contribuya a la conservación ya la utilización sostenible de la diversidad biológica, particularmente en los países en desarrollo, entre otras cosas, de conformidad con las decisiones adoptadas por la Conferencia de las Partes a raíz de las recomendaciones del órgano subsidiario de asesoramiento científico, técnico y tecnológico; y

12.c De conformidad con las disposiciones de los artículos 16, 18 y 20 , promoverán la utilización de los adelantos científicos en materia de investigaciones sobre diversidad biológica para la elaboración de métodos de conservación y utilización sostenible de los recursos biológicos, y cooperarán en esa esfera.

Convención Relativa a los Humedales de Importancia Internacional, especialmente como Hábitat de Aves Acuáticas (Convención Ramsar)

3.1 Las Partes Contratantes deberán elaborar y aplicar su planificación de forma que favorezca la conservación de los humedales incluidos en la Lista y, en la medida de lo posible, el uso racional de los humedales de su territorio.

4.1 Cada Parte Contratante fomentará la conservación de los humedales y de las aves acuáticas creando reservas naturales en aquéllos, estén o no incluidos en la Lista, y tomará las medidas adecuadas para su custodia.

Ramsar Convention (1971), UNCLOS (1982), Biodiversity Convention (1992) 
15. OBJETIVO DE DESARROLLO SOSTENIBLE 15: PROTEGER, RESTABLECER Y PROMOVER EL USO SOSTENIBLE DE LOS ECOSISTEMAS TERRESTRES, GESTIONAR LOS BOSQUES DE FORMA SOSTENIBLE, LUCHAR CONTRA LA DESERTIFICACIÓN, DETENER E INVERTIR LA DEGRADACIÓN DE LAS TIERRAS Y PONER FRENO A LA PÉRDIDA DE LA DIVERSIDAD BIOLÓGICA

Dentro del ODS 15, la meta 15.B plantea movilizar un volumen apreciable de recursos procedentes de todas las fuentes y a todos los niveles para financiar la gestión forestal sostenible y proporcionar incentivos adecuados a los países en desarrollo para que promuevan dicha gestión, en particular con miras a la conservación y la reforestación. Taking Root (DNV GL y Sustania, 2019) trabaja con pequeños agricultores en el norte de Nicaragua para animarlos a plantar árboles a cambio de ingresos provenientes de créditos de carbono o de productos forestales trazables. Utiliza técnicas GPS y visitas de campo para monitorear el crecimiento de los árboles en cada parcela, con el fin de generar créditos de carbono certificados por el estándar internacional "Plan Vivo". Estos créditos de carbono son vendidos por Taking Root en nombre de los agricultores, a quienes se les paga en efectivo. Cada granja y cada agricultor puede ser visto en línea con su mapa digital llamado Farm-Trace. La compañía estima que su programa de compensación de carbono emplea a más de 1.200 agricultores cada año, y ha resultado en la plantación de 2,2 millones de árboles. La compañía también trabaja con los agricultores para plantar y cosechar café y productos madereros que pueden ser rastreados mediante la web Farm-Trace, que también rastrea cuántos árboles han sido plantados, el área total reforestada, y cuántos ingresos han sido generados por los agricultores.

La meta 15.5 hace un llamamiento a la adopción de medidas urgentes y significativas para reducir la degradación de los hábitats naturales, detener la pérdida de la diversidad biológica y, para 2020, proteger las especies amenazadas y evitar su extinción. Pero la transformación del territorio por la producción de alimentos, combustibles o materias primas está dando lugar al comienzo de la sexta extinción, pues las tasas actuales de extinción son más altas de lo que cabría esperar (Lewis \& Maslin, 2015). El reciente informe de la Plataforma Intergubernamental de Ciencia y Política sobre Biodiversidad y Servicios de los Ecosistemas (IPBES) titulado El peligroso declive de la naturaleza sin precedentes, elaborado por un total de 145 expertos de más de 50 países, ha llegado a la conclusión de que la extinción de especies no hace más que acelerar. Para el presidente de IPBES, Robert Watson, "La salud de los ecosistemas de los que nosotros y todas las demás especies dependemos se está deteriorando a una velocidad nunca vista. Estamos erosionando los cimientos de las economías, los medios de vida, la seguridad alimentaria, la salud y la calidad de vida en todo el mundo" (IPBES, 2019). Esto impediría lograr las metas 15.1, 15.2 o 15.4 relacionadas con la conservación de ecosistemas, la gestión sostenible de los bosques o la conservación de ecosistemas montañosos. 


\begin{tabular}{|l|l|}
\hline \multicolumn{1}{|c|}{ Acuerdos y derechos afectados } \\
\hline \multicolumn{1}{|c|}{ Instrumento } & \multicolumn{1}{c|}{ Artículo } \\
\hline Convenio sobre la Diversi- & $\begin{array}{l}\text { 6. Cada Parte Contratante, con arreglo a sus condiciones y } \\
\text { capacidades particulares: } \\
\text { 6.a Elaborará estrategias, planes o programas nacionales para } \\
\text { la conservación y la utilización sostenible de la diversidad } \\
\text { biológica o adaptará para ese fin las estrategias, planes o } \\
\text { programas existentes, que habrán de reflejar, entre otras cosas, } \\
\text { las medidas establecidas en el presente Convenio que sean } \\
\text { pertinentes para la Parte Contratante interesada; y }\end{array}$ \\
6.b Integrará, en la medida de lo posible y según proceda, \\
la conservación y la utilización sostenible de la diversidad \\
biológica en los planes, programas y políticas sectoriales o \\
intersectoriales.
\end{tabular}

Ramsar Convention (1971), Biodiversity Convention (1992), UNCCD (1994) 
16. OBJETIVO DE DESARROLLO SOSTENIBLE 16: PROMOVER SOCIEDADES PACÍFICASE INCLUSIVAS PARA EL DESARROLLO SOSTENIBLE, FACILITAR EL ACCESO A LA JUSTICIA PARA TODOS Y CREAR INSTITUCIONES EFICACES, RESPONSABLES E INCLUSIVAS A TODOS LOS NIVELES

También la tecnología puede afectar positivamente al ODS 16, en particular las metas 16.5 Reducir considerablemente la corrupción y el soborno en todas sus formas y 16.6 Crear a todos los niveles instituciones eficaces y transparentes que rindan cuentas. Blockchain es una tecnología que permite garantizar el intercambio fiable de información, la seguridad de los datos, y el acceso constante y certero a los registros o transacciones digitales, de manera rápida, segura y eficiente. Con blockchain podemos imaginar, y esto favorece claramente el ODS 16, un mundo en el que los contratos están incrustados en código digital y almacenados en bases de datos transparentes y compartidas, protegidos contra el borrado, manipulación o reescritura. En este mundo, cada acuerdo, cada proceso, cada tarea y cada pago tendría un registro digital y una firma que podría ser identificada, validada, almacenada y compartida. Los individuos, las organizaciones, las máquinas y los algoritmos negociarían libremente e interaccionarían uno con el otro con poca fricción. Tanto es así, que ya se ha afirmado que Blockchain producirá cambios profundos, no solo en la naturaleza de las empresas, sino en cómo se financian y administran, cómo crean valor y cómo desempeñan funciones básicas como marketing y contabilidad; en algunos casos, los algoritmos reemplazarán a la administración por completo (Tapscott \& Tapscott, 2016).

Sin embargo, la computación cuántica del futuro podría resultar un riesgo de seguridad, cosa que no es posible con los procesadores de hoy. Un hacker equipado con una computadora cuántica podría usar un algoritmo para falsificar cualquier firma digital, hacerse pasar por ese usuario y apropiarse de sus activos digitales (Kiktenko et al., 2018). La mayoría de los especialistas piensan que esta hazaña requeriría una computadora que está a más de una década. Sin embargo, algunos investigadores sugieren que esto podría suceder antes lo que hace necesario la investigación de una nueva generación de protocolos de encriptación. Este es sólo un ejemplo de cómo la tecnología puede vulnerar los sistemas tecnológicos y, en última instancia, amenazar las libertades fundamentales (meta 16.10), en especial el derecho a la privacidad. 


\begin{tabular}{|l|l|}
\hline \multicolumn{1}{|c|}{ Acuerdos y derechos afectados } \\
\hline \multicolumn{1}{|c|}{ Instrumento } & \multicolumn{1}{c|}{ Artículo } \\
\hline Declaración universal de los homanos & $\begin{array}{l}\text { 12. Nadie será objeto de injerencias arbitrarias en su vida privada, } \\
\text { su familia, su domicilio o su correspondencia, ni de ataques a } \\
\text { su honra o su reputación. Toda persona tiene derecho a la } \\
\text { protección de la ley contra tales injerencias o ataques. } \\
\text { 19. Todo individuo tiene derecho a la libertad de opinión y } \\
\text { de expresión; este derecho incluye el no ser molestado a causa } \\
\text { de sus opiniones, el de investigar y recibir informaciones y } \\
\text { opiniones, y el de difundirlas, sin limitación de fronteras, por } \\
\text { cualquier medio de expresión. }\end{array}$ \\
\hline $\begin{array}{l}\text { Convención de las Naciones } \\
\text { Unidas contra la Corrupción }\end{array}$ & $\begin{array}{l}\text { La Convención de las Naciones Unidas contra la Corrupción } \\
\text { (UNCAC) es un instrumento internacional de lucha contra la } \\
\text { corrupción que es jurídicamente vinculante a nivel mundial. Se } \\
\text { exige a los Estados ratificantes que apliquen medidas contra la } \\
\text { corrupción que tienen como objetivo la prevención de la corrup- } \\
\text { ción, incluyendo el soborno nacional y extranjera, malversación, } \\
\text { tráfico de influencias y blanqueo de dinero. También tiene la } \\
\text { intención de fortalecer la aplicación de la ley internacional y } \\
\text { la cooperación judicial, proporcionando mecanismos legales } \\
\text { eficaces para la recuperación de activos, la asistencia técnica y } \\
\text { el intercambio de información. }\end{array}$ \\
\hline
\end{tabular}

UDHR (1948). UNCAC (2003)

\section{OBJETIVO DE DESARROLLO SOSTENIBLE 17: REVITALIZAR LA ALIANZA MUNDIAL PARA EL DESARROLLO SOSTENIBLE}

Entendemos que el ODS 17 es un objetivo "desiderativo" que hace referencia a un "deber ser compartido" de gobiernos, sector privado y sociedad civil. Sus metas invitan a promover la cooperación en materia de ciencia, tecnología e innovación, desarrollar tecnologías ecológicamente racionales y, en definitiva, el aumento de las capacidades tecnológicas. Por eso, desde el punto de vista de la tecnología, se trata de un "metaobjetivo" que remite a los 16 restantes, donde las capacidades tecnológicas se aplican. El desarrollo de la tecnología y su difusión, más que un deseo expresado en el ODS 17, tendría que estar presente en cada uno de ellos como eje transversal o vertebrador de la totalidad de la Agenda. Aunque, como hemos descrito, sus efectos inhibidores pueden generar un resultado ambiguo e incierto. 


\section{CONCLUSIÓN}

Los ODS son una apuesta inteligente, coordinada y decidida para afrontar la década que viene, la década de la acción; pero no son un fenómeno aislado que aparece por generación espontánea en 2015. Son la culminación de muchos años e instrumentos de trabajo que se han venido desarrollando por las universidades, instituciones privadas y multilaterales desde la década de los cincuenta. Para la consecución de dichas metas -que afectan a aspectos económicos, sociales, laborales, de género y ambientales- la tecnología aparece como el gran catalizador. Sin embargo, a pesar de las entusiastas perspectivas que la tecnología nos promete, es necesario abordar de forma crítica y sincera sus posibilidades y efectos. La tecnología está favoreciendo la aparición de formas más eficientes de cultivo, nuevas formas de comunicación y transmisión de contenidos para la educación, mayor eficiencia en el uso de la energía y/o sistemas avanzados de aprovechamiento del agua. Estas son solo algunas de las aplicaciones actuales más innovadoras. En un futuro próximo veremos aparecer nuevas aplicaciones y artefactos sorprendentes en nuestras sociedades. Sin embargo, al mismo tiempo, los efectos sistémicos del cambio climático, el intensivo consumo energético de la llamada cuarta revolución industrial o el incremento de las necesidades de consumo y crecimiento económico global pueden contrarrestar los efectos virtuosos de la tecnología.

Por otra parte, existen ciertos límites que proceden no tanto de las posibilidades tecnológicas como de las formas de gestión de personas y organizaciones. Si bien los ODS construyen un discurso retórico y persuasivo, las prácticas gubernamentales ineficientes a la hora de gestionar los recursos o las sobreactuaciones de las empresas -quizá buscando un efecto embellecedor, una nueva cara amable para ocultar sus deficiencias- puedan secuestrar el discurso. Con tal efecto la Agenda 2030 pasaría a la historia como una nueva marca de maquillaje, con una fantástica paleta de colores que no tuvo la capacidad de abordar de forma profunda y sistémica los problemas de la primera parte del siglo XXI.

Por último, tampoco se menciona con demasiada claridad el desarrollo de una ética de la sostenibilidad, esa condición de posibilidad para el desarrollo de unos valores cívicos globales. La integración de determinados valores por la ciudadanía -la constitución de sujetos cívicos que piensen globalmente y actúen localmente-, es la clave de una ciudadanía libre cuyo desarrollo no dependería tanto de instrumentos jurídicos coercitivos como de conductas racionales autónomas. La constitución de sujetos cívicos - polos de autogobierno- permitiría racionalizar el uso y consumo de los recursos, el transporte en ciudades y largas distancias y potenciar la colaboración como estrategia de resolución de problemas. Frente a esto la tecnología aparece, en muchas ocasiones, como una solución de final de tubería, es decir, la solución de un problema que podría haber sido evitado "en origen". 
Después de un estudio profundo y de una perspectiva crítica queda claro que la consecución de las metas planteadas - por su carácter interrelacionado y la magnitud de los problemas que se plantean- es extremadamente difícil. Por eso mismo, a pesar de las dificultades técnicas que puedan plantearse, resulta necesaria una voluntad moral firme que persevere pese a los obstáculos que pueda presentar la década que viene. Una voluntad general, que implica la participación de todos los actores sociales posibles; la participación desde los ámbitos más generales -representantes públicos, organizaciones, empresas, instituciones globales- hasta los espacios más locales -ciudades, asociaciones y ciudadanos individuales corresponsables-.

Los ODS no solo son un marco para la resolución de problemas, también sirven como instrumento de protección de esas exigencias de dignidad que son derechos humanos. Los derechos humanos ofrecen un marco legalmente vinculante y los ODS pueden contribuir sustancialmente a la realización de los derechos humanos. Por todo esto los ODS aparecen, al mismo tiempo, como un marco beneficioso pero incierto.

\section{BIBLIOGRAFÍA}

Andreu, A. (2017). Revisión crítica de la dimensión "Gobierno Corporativo" en los Índices de Sostenibilidad: análisis del ejercicio de la responsabilidad del Consejo de Administración en materia de RSC en las compañias del Ibex 35 español. Madrid: Universidad Pontificia Comillas.

Andreu, A. \& Fernández, J. L. (2011). De la RSC a la sostenibilidad corporativa: una evolución necesaria para la creación de valor. Harvard-Deusto Business Review, 207, 5-21. Recuperado de: https:/www.harvard-deusto.com/de-la-rsc-a-la-sostenibilidad-corporativa-una-evolucion-necesaria-para-la-creacion-de-valor

Andreu, A. \& Fernández, J. (2019, 17 de septiembre). La ambivalencia tecnológica para impulsar (¿o no?) los ODS. Telos. Cuadernos de comunicación, tecnología y sociedad, 111. Recuperado de https://telos.fundaciontelefonica.com/ambivalencia-tecnologica-para-impulsar-ods-onu/

Andreu, A. \& Fernández, J. (2019, 11 de octubre). ¿Por qué la transformación digital obliga a actualizar la Declaración Universal de los Derechos Humanos? Revista Ethic online. Recuperado de https://ethic.es/2019/10/transformacion-digital-tecnologia-derechos-humanos/

Bazán, C., Morena, J. d., \& Cortés, H. (2016). Guía para la integración de la Responsabilidad Social Corporativa. Barcelona: Wolters Kluwer.

Benke, K., \& Tomkins, B. (2017). Future food-production systems: vertical farming and controlled-environment agriculture. Sustainability: Science, Practice and Policy, 13 (1), 13-26. https://doi.org/10.1080/15487733.2017.1394054 
Briant Carant, J. (2017). Unheard voices: a critical discourse analysis of the Millennium Development Goals' evolution into the Sustainable Development Goals. Third World Quarterly, 38 (1), 16-41. https://doi.org/10.1080/01436597.2016.1166944 Brundtland, G. H. (1987). Report of the World Commission on environment and development: "our common future". United Nations. Recuperado de: http://www. un-documents.net/wced-ocf.htm

Buolamwini, J. \& Gebru, T. (2018). Gender shades: Intersectional accuracy disparities in commercial gender classification. In Conference on Fairness, Accountability and Transparency (pp. 77-91). Recuperado de: http://proceedings.mlr.press/v81/ buolamwini18a/buolamwini18a.pdf

Chui, M., Manyika, J. \& Miremadi, M. (2016, july). Where machines could replace humans-and where they can't (yet). McKinsey Quarterly. Recuperado de: https://www.mckinsey.com/business-functions/mckinsey-digital/our-insights/ where-machines-could-replace-humans-and-where-they-cant-yet

Christie, C., \& Nichols, M. (2004). Aeroponics: A Production System and Research Tool. Acta Hortic, 648, 185-190. https://doi.org/10.17660/actahortic.2004.648.22

Condliffe, J. (2017, 18 de enero). Los robots se quedarán con el trabajo humano, pero más lento de lo que se cree. MIT Technology Review en español. Recuperado de: https://www.technologyreview.es/s/6698/los-robots-se-quedaran-con-el-trabajo-humano-pero-mas-lento-de-lo-que-se-cree

Despommier, D. (2010). The Vertical Farm: Feeding the World in the 21st Century. New York: Picador.

Diffenbaugh, N. S., \& Burke, M. (2019). Global warming has increased global economic inequality. Proceedings of the National Academy of Sciences, 116 (20), 9808-9813. https://doi.org/10.1073/pnas.1816020116

DNV GL. (2018). Global Opportunity Report 2018. Høvik, Oslo: DNV GL, United Nations Global Compact \& Sustaina. Recuperado de: https://www.unglobalcompact.org/docs/publications/Global_Opportunity_Report 2018.pdf

DNV GL \& Sustania (2019). Global Opportunity Report 2019. DNV GL, United Nations Global Compact, Sustaina. Recuperado de: https://www.unglobalcompact.org/docs/publications/GOE 2019 Insights.pdf

Eccles, R. G., Ioannou, I., \& Serafeim, G. (2014). The impact of corporate sustainability on organizational processes and performance. Management Science, 60 (11), 2835-2857. https://doi.org/10.1287/mnsc.2014.1984

European Political Strategy Centre [EPSC] (2018). The Age of Artificial Intelligence: Towards a European Strategy for Human Centric Machines. European Political Strategy Centre. Recuperado de: https://ec.europa.eu/epsc/sites/epsc/ files/epsc strategicnote ai.pdf

Fernández-Mateo, J. (2015). Empresa, ética y responsabilidad: problemas epistemológicos, éticos y culturales. En Benavides, J. y Monfort, A. (eds.), Comunicación y empresa responsable (pp. 65-85). Pamplona: EUNSA. 
Franco-Barrera, A. J. (2018). Igualdade e sostibilidade. Pode a loita contra a mudanza climática reducir a desigualdade? RIPS: Revista de Investigaciones Políticas y Sociológicas, 17 (1), 9-26.https://doi.org/10.15304/rips.17.1.3938

Franco-Barrera, A. J. (2019a). Alteracións climáticas e mudanza democrática. Unha aproximación dende a ecoloxía política. Agora: Papeles de Filosofía, 38 (1), 123-144. https://doi.org/10.15304/ag.38.1.4610

Franco-Barrera, A J. (2019b). La revolución contra el cambio climático. Una aproximación a los retos de la acción climática. Eikasia: Revista de Filosofía, 89, 265-282.

Freeman, R. E. (1984). Strategic management: A stakeholder approach. Cambridge, UK: Cambridge University Press.

Friedman, M. (1966). Capitalismo y Libertad. Madrid: Rialp

Friedman, M. (1970). A Friedman doctrine: The social responsibility of business is to increase its profits. The New York Times Magazine, 13, 32-33.

Friedman, M., \& Friedman, R. (1990). Free to choose. San Diego (California, USA): Harcourt/Harvest.

Gerbens-Leenes, P.W., Mekonnen, M.M. and Hoekstra, A.Y. (2013). The water footprint of poultry, pork and beef: A comparative study in different countries and production systems. Water Resources and Industry, 1-2, 25-36. https://doi. org/10.1016/j.wri.2013.03.001

GeSI (2008). Smart 2020: Enabling the low carbon economy in the information age. The Climate Group, Global e-Sustainability Initiative. Recuperado de: https:// www.theclimategroup.org/sites/default/files/archive/files/Smart2020Report.pdf

Gjerdrum Pedersen, E. (2015). Corporate Social Responsibility. London: Sage.

Gladwin, T. N., Kennelly, J. J., \& Krause, T. S. (1995). Shifting paradigms for sustainable development: Implications for management theory and research. Academy of Management Review, 20 (4), 874-907. https://doi.org/10.5465/ amr.1995.9512280024

Gómez-Cotta, C. (2019, 29 de marzo). Llegan los invernaderos verticales. Revista Ethic. Recuperado de: https://ethic.es/2019/03/agricultura-invernaderos-verticales/ Gorrochategui, N., Martins de Oliveira, V., Hernández Bernal, A., \& Moreno Garzón, L. (2016). Responsabilidad Social de las Organizaciones (RSO): Aportes teórico-prácticos para lograr los Objetivos de Desarrollo Sostenible en América Latina. Bogotá: Ediciones USTA.

Gosch, M., \& Duque, A. (2016). Implantación eficiente de modelos de Responsabilidad Social Corporativa: El desafío de la Sostenibilidad. Madrid: UHY Fay \& Co.

Hayek, F. A. (2009). Camino de servidumbre. Madrid: Alianza Editorial.

Instituto Danés de Derechos Humanos (2019). La guía de los derechos humanos a los ODS. Recuperado de http://sdg.humanrights.dk/es/node/10 
IPBES (2019). Nature's Dangerous Decline 'Unprecedented'; Species Extinction Rates 'Accelerating'. Intergovernmental Science-Policy Platform on Biodiversity and Ecosystem Services (IPBES) Recuperado de: https://www.ipbes.net/news/ Media-Release-Global-Assessment

IPCC (2007). Climate change 2007: the physical science basis: summary for policymakers. Intergovernmental Panel on Climate Change. Recuperado de: https:// www.ipcc.ch/report/ar4/wg1/

IPCC (2019). IPCC Special Report on the Ocean and Cryosphere in a Changing Climate. Summary for Policymakers. [H.-O. Pörtner, D.C. Roberts, V. Masson-Delmotte, P. Zhai, M. Tignor, E. Poloczanska, K. Mintenbeck, M. Nicolai, A. Okem, J. Petzold, B. Rama, N. Weyer (eds.)]. En prensa.

IRP (2018). The Weight of Cities: Resource Requirements of Future Urbanization. Swilling, M., Hajer, M., Baynes, T., Bergesen, J., Labbé, F., Musango, J.K., Ramaswami, A., Robinson, B., Salat, S., Suh, S., Currie, P., Fang, A., Hanson, A. Kruit, K., Reiner, M., Smit, S. \& Tabory, S. A. Report by the International Resource Panel. United Nations Environment Programme, Nairobi, Kenya. Recuperado de: https://www.resourcepanel.org/reports/weight-cities

Jambeck, J. R., Geyer, R., Wilcox, C., Siegler, T. R., Perryman, M., Andrady, A., ... \& Law, K. L. (2015). Plastic waste inputs from land into the ocean. Science, 347 (6223), 768-771. https://doi.org/10.1126/science.1260352

Jang, B., Gutman, E., Stucki, N., Seitz, B. F., Wendel-García, P. D., Newton, T., ... \& Nelson, B. J. (2015). Undulatory locomotion of magnetic multilink nanoswimmers. Nano letters, 15 (7), 4829-4833. https://doi.org/10.1021/acs. nanolett.5b01981

Jänicke, M., Mönch, H., Ranneberg, T., \& Simonis, U. E. (1989). Economic structure and environmental impacts: East-West comParísons. Environmentalist, 9 (3), 171-183. https://doi.org/10.1007/bf02240467

Jiménez, J. (2019, 21 de mayo). China controla muchos materiales esenciales para el mundo tecnológico: energía, movilidad y dispositivos ante la guerra comercial. Xataca. Recuperado de: https://www.xataka.com/investigacion/ china-controla-muchos-materiales-esenciales-mundo-tecnologico-energia-movilidad-dispositivos-guerra-comercial

Kiktenko, E. O., Pozhar, N. O., Anufriev, M. N., Trushechkin, A. S., Yunusov, R. R., Kurochkin, Y. V., ... \& Fedorov, A. K. (2018). Quantum-secured blockchain. Quantum Science and Technology, 3 (3), 035004 https://doi.org/10.1088/2058-9565/aabc6b

Krishnamurthy, R. (2014, 25 de julio). Vertical Farming: Singapore's Solution to Feed the Local Urban Population. Permaculture Research Institute. Recuperado de: https://permaculturenews.org/2014/07/25/vertical-farming-singapores-solution-feed-local-urban-population/ 
Lewis, S. L. \& Maslin, M. A. (2015). Defining the anthropocene. Nature, 519 (7542), 171. https://doi.org/10.1038/nature14258

Malenbaum, W. (1978). World demand for raw materials in 1985 and 2000. United States: McGraw-Hill.

Naciones Unidas (2019). Informe de los Objetivos de Desarrollo Sostenible. Departamento de Asuntos Económicos y Sociales (DESA). Recuperado de: https:// unstats.un.org/sdgs/report/2019/The-Sustainable-Development-Goals-Report-2019 Spanish.pdf

Nicolaides, D., Cebon, D. \& Miles, J. (2017). Prospects for Electrification of Road Freight. IEEE Systems Journal, 12 (2), 1838-1849. https://doi.org/10.1109/ jsyst.2017.2691408

Oberle, B., Bringezu, S., Hatfield-Dodds, S., Hellweg, S., Schandl, H., Clement, J., ... \& Ekins, P. (2019). Global Resources Outlook 2019: Natural Resources for the Future We Want. A Report of the International Resource Panel. United Nations Environment Programme. Nairobi, Kenya. Recuperado de: https://www. resourcepanel.org/sites/default/files/documents/document/media/unep 252 global resource outlook 2019 web.pdf

OECD (2018). Private Philanthropy for Development, The Development Dimension. OECD Publishing. Recuperado de: https://doi.org/10.1787/9789264085190-en. Opschoor, J. B., de Bruyn, S. M., van den Bergh, J. C. J. M. \& van der Straaten, J. (1997). Structural change, growth and dematerialization. An empirical analysis. Economy and ecosystems in change, 201-231.

Papajak, U. (2017, 27 de noviembre). Can the Brooklyn Microgrid project revolutionise the energy market? Medium. Recuperado de: https://medium.com/ thebeammagazine/can-the-brooklyn-microgrid-project-revolutionise-the-energy-market-ae2c13ec0341

Politano, C. (2018, febrero). Regenerating the Planet with Blockchain. Medium. Recuperado de: https://medium.com/regen-network/regenerating-the-planet-with-blockchain-d75841505447

Rasche, A. \& Kell, G. (2010). The United Nations Global Compact: Achievements, Trends and Challenges. Cambridge, UK: Cambridge University Press.

Rifkin, J. (2010). La civilización empática. Barcelona: Paidós.

Rochman, C. M. (2016). Strategies for reducing ocean plastic debris should be diverse and guided by science. Environmental Research Letters, 11 (4), 041001. https://doi.org/10.1088/1748-9326/11/4/041001

Romm, J., Rosenfeld, A. \& Herrmann, S. (1999). The Internet economy and global warming: A scenario of the impact of e-commerce on energy and the environment. Center for Energy and Climate Solutions, Global Environment and Technology Foundation. 
Schwab, K. (2016). The Fourth Industrial Revolution. Cologny/Geneva, Switzerland: World Economic Forum.

Sherman, P. \& Van Sebille, E. (2016). Modeling marine surface microplastic transport to assess optimal removal locations. Environmental Research Letters, 11 (1), 014006. https://doi.org/10.1088/1748-9326/11/1/014006

Siemens (2017). eHighway - Electrification of road freight transport. Recuperado de: https://assets.new.siemens.com/siemens/assets/api/uuid:7bcd4aee10a34603eea30c4e8b8941478c164092/version:1500537078/ehighway-2017.pdf

Steadman, I. (2013, 11 de febrero). IBM's Watson is better at diagnosing cancer than human doctors. Technology. Recuperado de: https://www.wired.co.uk/ article/ibm-watson-medical-doctor

Strubell, E., Ganesh, A. \& McCallum, A. (2019, julio). Energy and Policy Considerations for Deep Learning in NLP. Annual Meeting of the Association for Computational Linguistics. Florence, Italy. Recuperado de: https://arxiv.org/ abs/1906.02243

Tapscott, D. \& Tapscott, A. (2016). Blockchain Revolution: How the Technology Behind Bitcoin is Changing Money, Business and the World. New York: Penguin Random House.

Thompson, C. (2011, 7 de julio). How Khan Academy is changing the rules of education. Wired Magazine. Recuperado de: https://www.wired.com/2011/07/ ff khan/

UNESCO (2016). La educación al servicio de los pueblos y el planeta: creación de futuros sostenibles para todos. Informe de Seguimiento de la Educación en el Mundo. Recuperado de: https://unesdoc.unesco.org/ark:/48223/pf0000248526

Vanham, D., Hoekstra, A.Y. \& Bidoglio, G. (2013). Potential water saving through changes in European diets. Environment International, 61, 45-56. https://doi. org/10.1016/j.envint.2013.09.011

WHO \& UNICEF (2017). Progress on drinking water, sanitation and hygiene: 2017 update and SDG baselines. Geneva: World Health Organization and the United Nations Children's Fund. Recuperado de: https://www.unicef.org/publications/ files/Progress on Drinking Water Sanitation and Hygiene 2017.pdf

Zhang, L. (2014). The Abdul Latif Jameel Poverty Action Lab: Bringing Evidence-based Policy into International Development. Harvard International Review, 35 (4), 4-5. Recuperado de: http://www.jstor.org/stable/43650227 


\section{DECLARACIONES, ACUERDOS Y CONVENIOS}

Basel Convention (1989). Basel Convention on the Control of Transboundary Movements of Hazardous Wastes and their Disposal. Recuperado de: https://treaties. un.org/Pages/ViewDetails.aspx?src=TREATY\& mtdsg no=XXVII-3\& \&hapter $=27$ \& clang $=$ en

Biodiversity Convention (1992). Convention on Biological Diversity. Recuperado de: https://treaties.un.org $/$ Pages $/$ ViewDetails.aspx?src $=$ TREATY\& $m$ tdsg no $=X X$ VII-8\& chapter $=27 \&$ clang $=$ en

CEDAW (1979). Convention on the elimination of all forms of discrimination against women. United Nations General Assembly. Recuperado de: https://www.ohchr. org/EN/ProfessionalInterest/Pages/CEDAW.aspx

DEVAW (1993). Declaration on the Elimination of Violence against Women. United Nations General Assembly. Recuperado de: https://www.ohchr.org/EN/ProfessionalInterest/Pages/ViolenceAgainstWomen.aspx

ICCPR (1966). International Covenant on Civil and Political Rights. United Nations General Assembly. Recuperado de: https://www.ohchr.org/en/professionalinterest/pages/ccpr.aspx

ICESCR (1966). International Covenant on Economic, Social and Cultural Rights. United Nations General Assembly. Recuperado de: https://www.ohchr.org/EN/ ProfessionalInterest/Pages/CESCR.aspx

Ramsar Convention (1971). Ramsar Convention on Wetlands of International Importance Especially as Waterfowl Habitat. Recuperado de: https://treaties.un.org/ Pages/showDetails.aspx?objid $=0800000280104$ c20

UNCAC (2003). United Nations Convention against Corruption. United Nations General Assembly. Recuperado de: https://treaties.un.org/pages/ViewDetails. aspx ?src $=$ TREATY\& $m$ tdsg no $=X V I I I-14 \&$ chapter $=18$

UDHR (1948). Universal declaration of human rights. United Nations General Assembly. Recuperado de: https:/www.un.org/en/universal-declaration-human-rights/ UNCCD (1994). United Nations Convention to Combat Desertification in Those Countries Experiencing Serious Drought and/or Desertification, Particularly in Africa. Recuperado de: https://treaties.un.org/doc/Treaties/1996/12/19961226\%20 01-46\%20PM/Ch_XXVII_10p.pdf

UNCLOS (1982). Convention on the Law of the Sea. United Nations. Recuperado de: https://treaties.un.org/Pages/ViewDetailsIII.aspx?src=TREATY\&mtdsg $\underline{\text { no }=X X I-6 \& \text { chapter }=21 \& \text { Temp }=m t d s g 3 \& \text { clang }=\text { en }}$

UNCRC (1989). Convention on the Rights of the Child. United Nations General Assembly, Treaty Series, 1577 (3). Recuperado de: http://wunrn.org/referencel pdf/Convention_Rights_Child.PDF 
UNFCCC (1992). United Nations Framework Convention on Climate Change. Report n. FCCC/INFORMAL/84. Recuperado de: https://unfccc.int/resource/docs/ convkp/conveng.pdf

UNFCCC (2015). Adoption of the París Agreement. Report n. FCCC/CP/2015/L.9/

Rev.1. Recuperado de: http://unfccc.int/resource/docs/2015/cop21/eng/109r01.pdf 